\title{
Transcriptional signature of an adult brain tumor in Drosophila Thomas Loop ${ }^{1}$, Ronny Leemans ${ }^{1}$, Urs Stiefel ${ }^{1}$, Leandro Hermida ${ }^{2}$, Boris Egger ${ }^{1}$, Fukang Xie ${ }^{1}$, Michael Primige ${ }^{2}$, Ulrich Certa ${ }^{3}$, Karl- Friedrich Fischbach ${ }^{4}$, Heinrich Reichert ${ }^{1}$ and Frank Hirth ${ }^{* 1}$
}

Address: ${ }^{1}$ Institute of Zoology, Biocenter/Pharmacenter, University of Basel, Klingelbergstr. 50, CH-4056 Basel, Switzerland, ${ }^{2}$ Biocenter, University of Basel, Klingelbergstr. 70, CH-4056 Basel, Switzerland, ${ }^{3}$ Roche Genetics Pharmaceuticals Division, F. Hoffmann-La Roche Ltd, CH-4070 Basel, Switzerland and ${ }^{4}$ Institute of Biology III, University of Freiburg, Schaenzlestrasse 1, D-79104 Freiburg, Germany

Email: Thomas Loop - Thomas.Loop@unibas.ch; Ronny Leemans - Ronny.Leemans@unibas.ch; Urs Stiefel - Urs.Stiefel@unibas.ch; Leandro Hermida - Leandro.Hermida@unibas.ch; Boris Egger - Boris.Egger@welc.cam.ac.uk; Fukang Xie - frankxie@gzsums.edu.cn; Michael Primig - Michael.Primig@unibas.ch; Ulrich Certa - Ulrich.Certa@Roche.com; Karl-Friedrich Fischbach - kff@uni-freiburg.de; Heinrich Reichert - Heinrich.Reichert@unibas.ch; Frank Hirth* - Frank.Hirth@unibas.ch

* Corresponding author

Published: 16 April 2004

BMC Genomics 2004, 5:24
Received: 19 December 2003

Accepted: 16 April 2004

This article is available from: http://www.biomedcentral.com/I47I-2/64/5/24

(C) 2004 Loop et al; licensee BioMed Central Ltd. This is an Open Access article: verbatim copying and redistribution of this article are permitted in all media for any purpose, provided this notice is preserved along with the article's original URL.

\begin{abstract}
Background: Mutations and gene expression alterations in brain tumors have been extensively investigated, however the causes of brain tumorigenesis are largely unknown. Animal models are necessary to correlate altered transcriptional activity and tumor phenotype and to better understand how these alterations cause malignant growth. In order to gain insights into the in vivo transcriptional activity associated with a brain tumor, we carried out genome-wide microarray expression analyses of an adult brain tumor in Drosophila caused by homozygous mutation in the tumor suppressor gene brain tumor (brat).
\end{abstract}

Results: Two independent genome-wide gene expression studies using two different oligonucleotide microarray platforms were used to compare the transcriptome of adult wildtype flies with mutants displaying the adult brat ${ }^{\mathrm{K} 06028}$ mutant brain tumor. Cross-validation and stringent statistical criteria identified a core transcriptional signature of brat ${ }^{\mathrm{k} 06028}$ neoplastic tissue. We find significant expression level changes for $32 \mathrm{I}$ annotated genes associated with the adult neoplastic brat ${ }^{\mathrm{K} 06028}$ tissue indicating elevated and aberrant metabolic and cell cycle activity, upregulation of the basal transcriptional machinery, as well as elevated and aberrant activity of ribosome synthesis and translation control. One fifth of these genes show homology to known mammalian genes involved in cancer formation.

Conclusion: Our results identify for the first time the genome-wide transcriptional alterations associated with an adult brain tumor in Drosophila and reveal insights into the possible mechanisms of tumor formation caused by homozygous mutation of the translational repressor brat.

\section{Background}

Cancer is a multistep process, which involves loss of cell proliferation control, resistance to cell death, and invasion as well as metastasis. This process is often associated with multiple and progressive genetic alterations. Protooncogenes are activated in a dominant fashion by mutation, chromosome translocation or gene amplification, whereas tumor suppressor genes are inactivated or lost by 
mutation, chromosome loss, mitotic recombination or gene conversion [1-3].

Mutations and gene expression alterations in brain tumors have been extensively investigated. For example, data has been accumulated for the cerebellar tumor medulloblastoma which is the most common malignant brain tumor in children [4]. In addition to chromosome loss, medulloblastomas overexpress certain genes, including c-myc, pax5, and zic, all of which encode transcription factors [5-7]. Thus, animal models of brain tumors are required to gain insights into the correlation of genetic alterations and tumor phenotype and to better understand how genetic alterations cause malignant neoplasm $[4,8]$. To better understand the genetic alterations associated with brain tumors in vivo, the fruitfly Drosophila melanogaster is an excellent model system for which unprecedented genetic and transgenic technologies as well as entire genome sequence information are available $[9,10]$. Indeed, more than two thirds of the known human cancer genes are thought to have Drosophila homologs $[11,12]$, and various studies have shown that genetic inactivation or misregulation of Drosophila oncogenes or tumor suppressor genes lead to neoplasms that display characteristic features of malignant growth like in human cancer [13-15]. The level of gene and pathway conservation, the similarity of cellular processes, and the emerging evidence of functional conservation of Drosophila genes that are homologous to mammalian oncogenes or tumor suppressor genes, indicate that studies of tumorigenesis in flies can directly contribute to the understanding of human brain tumors $[16,17]$.

One of the earlier studies on mutations causing malignant neoplasms in Drosophila examined 12 recessive lethal mutations affecting the optic neuroblasts and ganglion mother cells in the larval brain, the imaginal discs, and the hematopoietic organs [13]. Among others, it could be shown, that a mutation in the lethal (2) giant larvae (lgl) gene leads to a failure of the optic neuroblasts of the inner and outer formation centers and the ganglion mother cells (GMCs) to generate adult neurons. The neuroblasts and GMCs proliferated extensively, causing a dramatic enlargement of the larval brain hemispheres. Upon transplantation of neoplastic tissue into wildtype hosts, the transplanted tissues invaded the body cavities, the abdomen, the thorax, the ovaries, the gut, and the thoracic muscles [13].

Further investigation of mutations in the $d l g 1$ and $l g l$ genes revealed that the resulting phenotypes exhibited most of the characteristics defining neoplastic growth in vertebrates, including rapid growth both in situ and in culture, defective intercellular junctions, low adhesiveness in between cells, defective intercellular communication, absence of terminal differentiation, lack of response to ecdysone, invasiveness, and lethality to the host ([13], reviewed in [18]).

Furthermore, it is known that expression of an activated form of RAS1 (RAS1V12) in Drosophila imaginal discs is leading to ectopic cell proliferation and hyperplastic tissue growth [19]. The mutational activation of the human homolog of Ras is associated with a wide variety of human tumors (reviewed in [20]). When RASV12 expression is combined with inactivation of scribbled. (scrib), lethal (2) giant larvae (lgl), discs large 1 (dlg1), bazooka (baz), stardust(sdt) and Cdc42 in Drosophila larvae, migration, invasion of tumor tissue and secondary tumor foundation can be found [15]. Another Drosophila gene possessing tumor suppressor properties is warts (wts). Flies homozygous for strong $w t s$ alleles show overproliferation in the imaginal discs and the central nervous system leading to pupal lethality. The observed cellular clones where irregular in shape, unpatterned and formed folded lobes. The cells to be found in $w t s$ mutant clones were larger than neighboring wildtype cells [21]. The mammalian homolog of $w t s$, LATS1, is also known for causing soft-tissue sarcomas and ovarian stromal cell tumors when

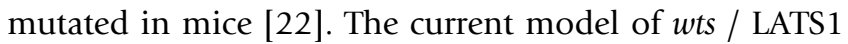
function suggests interaction with CyclinA / Cdc2, linking it directly to the cell cycle ([23], reviewed in [24]).

Mutations in the Drosophila gene salvador (sav) have been associated with increased cell growth and an increase in cell number. Also, Sav has been suggested to interact directly with Wts and thereby contributing to its function [25].

In this report, we have determined at the full genome level the transcriptional signature of an adult brain tumor in Drosophila caused by homozygous mutation in the tumor suppressor gene brain tumor (brat). This gene encodes a member of the conserved NHL family of proteins, which appear to regulate differentiation and growth. These factors have been directly implicated in human tumor formation $[26,27]$. Based on the analysis of loss- and gain-offunction experiments, Brat acts in translation repression, ribosomal RNA synthesis, and negative regulation of cell growth [28-30]. Structural analysis indicates that the NHL beta-propeller is the essential domain for both the translational repression and cell growth inhibitory activities of Brat [31]. Inactivation of brat results in neoplastic overgrowth and tumor formation in the larval brain and generally causes lethality in the larval third instar and pupal stages [32]. It has been hypothesized that in brat loss-offunction larvae the optic neuroblasts and ganglion mother cells are incapable of generating neurons and repesent the source of the brain tumor [33]. Tumor cells derived from homozygous brat larval brain tissue can 
grow not only in situ, but also after transplantation into adult host flies. The transplanted cells grow rapidly, forming metastases and secondary malignant tumors, and finally kill their host [34].

Here we focus on the strong neoplastic adult brain phenotype caused by homozygous mutation of the brat ${ }^{k 06028}$ allele. To analyze the transcriptional activity associated with this brain tumor, we carried out two independent genome-wide microarray expression studies using two different oligonucleotide array platforms to compare adult wildtype flies with flies displaying the adult brat ${ }^{k 06028}$ mutant brain tumor. Our experiments identified 321 annotated genes that showed highly significant $(p<=0.0001)$ changes in expression levels due to loss of the tumor suppressor activity of brat. One fifth of these genes show homology to known mammalian genes involved in cancer formation. We observed significant upregulation of genes involved in the control of asymmetric neuroblast division. We also found significant upregulation of genes involved in ribosome biogenesis, translation, and RNA processing, suggesting a link between the tumor suppressor activity of brat and its role as a translational repressor during Drosophila development.

\section{Results \\ Adult homozygous brat ${ }^{\mathrm{0} 0628}$ mutants show a strong neoplastic brain phenotype}

The brat mutant allele brat ${ }^{k 06028}$ was generated by a Plac W transposon insertion in the non-coding Exon 4 of the brat locus lying immediately upstream of the transcriptional start site [28,32]. Larvae homozygous for this insertion manifest a strong neoplastic brain phenotype. We found that $15 \%(n=979)$ of homozygous brat ${ }^{k 06028}$ mutants eclose. These homozygous adult brat ${ }^{k 06028}$ mutants show limited motility compared to Oregon R wildtype flies and their lifespan is strongly reduced; most of the homozygous brat ${ }^{k 06028}$ mutants die after the first 10 days. Histological analysis showed that homozygous adult brat ${ }^{k 06028}$ mutants display a pronounced overproliferation in their brains as compared to Oregon R wildtype brains (Figure 1). The penetrance of this phenotype is $100 \%(\mathrm{n}=$ 300). Most of the newly hatched brat ${ }^{k 06028}$ mutants showed a head capsule completely filled with neoplastic tissue. In addition, we observed ectopic neuropil-like structures; these structures appeared bilaterally in ventromedial positions dorsal to the central brain complex and more ventro-laterally to the optic lobes (Figure 1B, arrowheads). In paraffin sections the size of the central brain structures and the optic lobes of brat ${ }^{k 06028}$ mutants appeared reduced as compared to the wildtype, however, the overall morphology of neuropil subdivisions in these brains was retained.
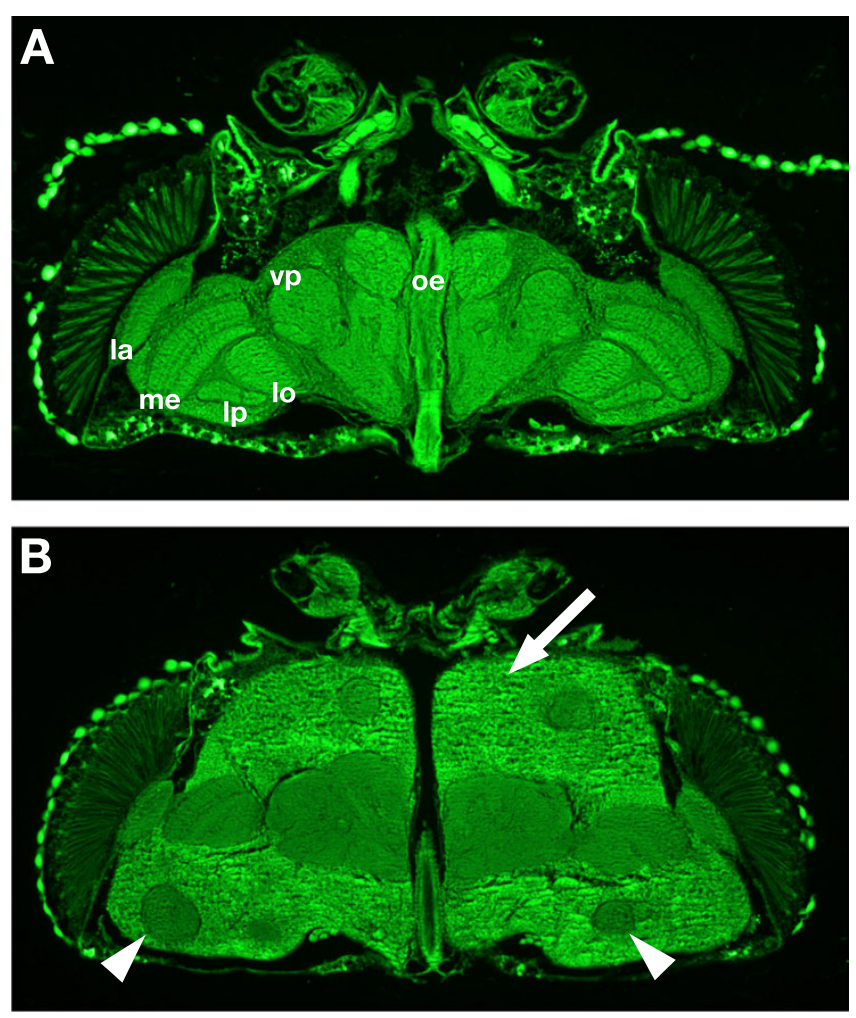

Figure I

Adult flies homozygous for the brat ${ }^{k 06028}$ allele show a strong neoplastic brain phenotype. Horizontal $7 \mu \mathrm{m}$ paraffin sections at the level of the oesophagus (oe) of the heads of two days old adult Oregon R wildtype (A) and brat ${ }^{k 06028}$ (B) flies. Homozygous adult bratk06028 mutants display a pronounced neoplastic phenotype in their heads ( $B$, arrow) and ectopic neuropil-like structures can be observed ( $B$, arrowheads). The size of several neuropil structures like lamina (la), medulla (me), lobula (lo), lobula plate (Ip), antennal lobe (al), and ventrolateral protocerebrum (vp) appears reduced (B, compare to wildtype in A). However, their overall morphology appears to be unaffected, suggesting that the cells giving rise to these neuropil structures differentiated normally in homozygous adult brat ${ }^{k 06028}$ mutants.

\section{Transcriptional signature of the adult brat ${ }^{\mathrm{k} 06028}$ mutant} brain tumor

In order to gain insights into the genetic alterations associated with a fully developed brain tumor in vivo, we determined at the full genome level the transcriptome of the neoplastic brain tumors caused by homozygous brat ${ }^{k 06028}$ mutation as compared to wildtype brain. To ensure crossvalidation and increased significance of our results, we conducted two independent genome-wide gene expression studies to compare wildtype flies with homozygous brat $^{k 06028}$ flies using two different oligonucleotide array platforms (Table 1). In the first experiment, RNA was 
Table I: Overview of the array experiments

\begin{tabular}{|c|c|c|c|}
\hline & & Experiment $\mathrm{A}$ & Experiment B \\
\hline \multirow[t]{2}{*}{ RNA source } & brat tumor & adult brat ${ }^{[\mathrm{k06028}]}$ heads & adult brat ${ }^{[\mathrm{k06028}]}$ brains \\
\hline & control & Oregon RS heads & brat ${ }^{[k 06028]}$ jumpout brains \\
\hline Arrays used & & roDromega full genome & Affymetrix full genome \\
\hline Number of replicates & & 5 Oregon RS against 6 brat ${ }^{[\mathrm{k} 06028]}$ & 6 brat ${ }^{[k 06028]}$ jumpout against 6 brat $[\mathrm{k} 06028]$ \\
\hline Signal amplification & & no & yes \\
\hline Differentially expressed genes & & 725 & 1888 \\
\hline Overlap between the experiments & & & \\
\hline
\end{tabular}

Overview of the two independent genome-wide gene expression studies using two different oligonucleotide array platforms to compare adult control flies with flies displaying the adult brat ${ }^{\mathrm{K} 06028}$ mutant brain tumor. Row I and Row2 indicate the source from which total RNA was extracted. Row 1 indicates source of tumor tissue, Row 2 indicates source of control tissue used in the experiments. For experiment $A$ (left column), total RNA was isolated from homozygous bratk06028 mutant heads (row I) as compared to total RNA isolated from Oregon R wildtype heads (row 2). For experiment B (right column), total RNA was isolated from dissected homozygous bratk06028 mutant brains (row I) as compared to total RNA isolated from dissected brains derived from flies generated by transposon excision of the brat ${ }^{k 06028} \mathrm{P}$-element (termed A2, brat ${ }^{\mathrm{k} 06028}$ jumpout; row 2). Row 3 denotes the two different Affymetrix oligonucelotide arrays used. Row 4 indicates the number of replicates carried out per condition for experiment $A$ and experiment $B$, respectively. Row 5 displays whether or not a signal amplification step has been performed following cRNA hybridization to the arrays. Row 6 presents the number of transcripts differentially expressed between conditions for experiment $A$ and experiment B, respectively. Row 7 indicates the number of genes that passed the filter criteria in both experiments.

extracted from homozygous adult bratk06028 fly heads and from isolated adult fly heads of Oregon $\mathrm{R}$ as control. The labeled cRNA of this experiment was hybridized to custom made full-genome GeneChips (roDROMEGa, experiment A). In the second experiment, RNA was extracted from dissected adult brains, and hybridization of labeled cRNA to commercially available full-genome Gene Chips involved a signal amplification step (DrosGenome1, experiment B; see materials and methods). Moreover, in this second experiment, the transcriptome of dissected adult brains of homozygous brat ${ }^{k 06028}$ mutants was compared to dissected adult brains of flies generated by transposon excision of the brat ${ }^{k 06028}$ P-element (termed bratk06028 jumpout, see materials and methods). Precise transposon excision resulted in reversion of the brat ${ }^{k 06028}$ neoplastic brain phenotype to wildtype-like brain (data not shown).

Stringent quality control and filtering for the two resulting data sets was done independently (see materials and methods). After analysis, 1778 transcripts in the wildtype condition and 2955 transcripts in the bratk06028 condition of experiment A were statistically judged as present. This represents $12.7 \%$ and $21 \%$ of all transcripts on the roDROMEGa array, respectively. In experiment B, 5063 transcripts were judged as present in the wildtype-like bratk06028 jumpout condition and 4981 in the brat ${ }^{k 06028}$ condition. This represents $36.3 \%$ and $35.7 \%$ of all transcripts on the DrosGenome1 array, respectively. Transcripts in both datasets were considered as differentially expressed when the change between conditions was larger than 2fold, their signal strength was above 10 in the condition with the higher expression level, and the change had a significance value of $\mathrm{p} \leq 0.0001$ ( $\mathrm{t}$-test). In experiment A 725 transcripts were judged as differentially expressed, whereas in experiment B 1888 transcripts were judged as differentially expressed in the brat ${ }^{k 06028}$ tumor condition (Table 1).

\section{The core set of genes differentially expressed in brat ${ }^{\mathrm{k} 0628}$ neoplasms}

To strengthen the significance of our data, we considered those genes for further analysis that passed the filter criteria in both experiments. This was the case for 321 transcripts, representing a core transcriptional signature that characterizes the neoplastic tissue of adult homozygous brat ${ }^{k 06028}$ mutants in a highly reproducible manner (Table 1). In both experiments, the majority of the 321 differentially regulated genes (279) showed an increased expression level in neoplastic adult brat ${ }^{k 06028}$ mutants. 42 transcripts out of 321 differentially regulated genes showed a decreased expression level in the bratk06028 condition. (5 transcripts out of the 321 genes showed an opposite differential expression change in experiment A and B). As shown in Figure 2, the majority of the 321 genes differentially regulated in $b_{r a t}{ }^{k 06028}$ neoplasms displayed comparable expression level changes in both experiments. Only 88 genes showed significantly higher expression level changes in experiment $\mathrm{B}$ as compared to experiment $\mathrm{A}$. This may be due to the fact that in experiment B cRNA hybridization to the array involved a signal amplification step (see materials and methods). 


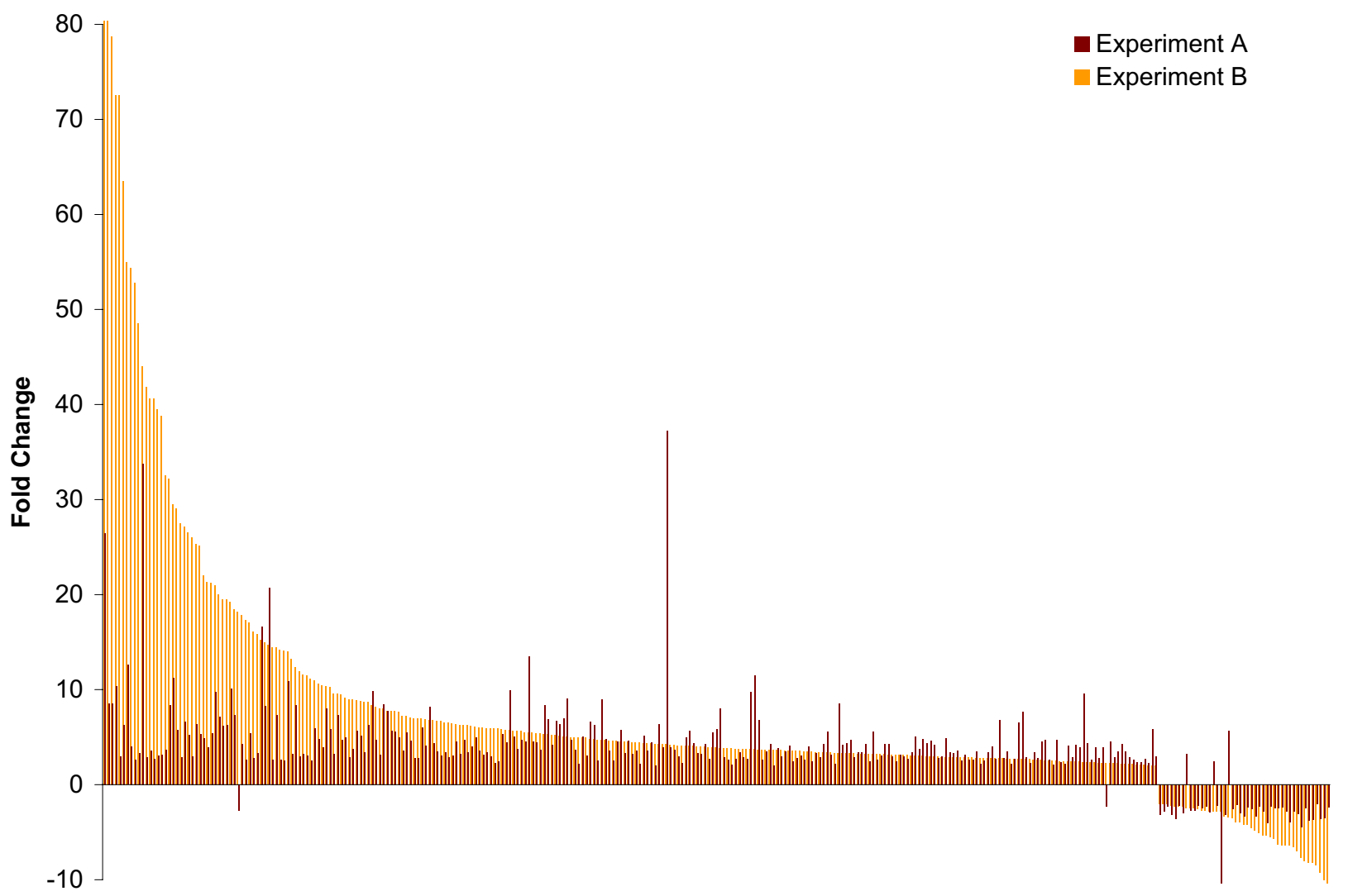

\section{Figure 2}

Expression level changes observed for the $32 \mathrm{I}$ genes identified in both oligonucleotide array experiments as differentially regulated in the brat tumor condition. $X$-coordinate shows relative fold-changes for each individual gene ( $y$-coordinate) depicted in red for experiment $A$ and depicted in orange for experiment $B$, respectively. Note that the two experiments $A$ and $B$ disagree on the differential expression level changes only for five transcripts. Please note that the highest expression levels are cut at a value of 80 due to the scaling of the $y$-axis.

The 321 genes differentially expressed in both experiments were grouped into functional classes according to their annotation in Flybase. The function of most of the differentially expressed transcripts were unknown ( $\mathrm{n}=$ 67). A list of these genes is shown in Figure 8. The remaining genes of known function were grouped into the functional classes metabolism $(\mathrm{n}=56)$, cytoskeleton/structural proteins $(\mathrm{n}=31)$, RNA binding/processing $(\mathrm{n}=27)$, transcription/replication/repair $(\mathrm{n}=20)$, translation $(\mathrm{n}=19)$, cell cycle $(\mathrm{n}=18)$, transcriptional regulation $(\mathrm{n}=17)$ chromatin structure $(\mathrm{n}=13)$, signal transduction $(\mathrm{n}=12)$, chaperones $(\mathrm{n}=$ $11)$, transport $(\mathrm{n}=10)$, proteolytic systems $(\mathrm{n}=8)$, stress response $(\mathrm{n}=7)$, cell surface receptors/CAMs/ion channels ( $\mathrm{n}$ $=4)$, and apoptosis $(\mathrm{n}=1)$. You can find a list of these 321 genes along with the fold change between experiments in Supplementary Table 3 [see Additional file 3].

\section{Genes involved in metabolism, cell cycle and apoptosis}

Neoplastic overgrowth involves essential alterations in cell physiology, loss of cell proliferation control and resistance to cell death. Accordingly, we expected to observe the differential expression of genes linked to metabolism, cell cycle regulation and apoptosis in our gene expression profile studies. Indeed, transcript profiling of brat ${ }^{k 06028}$ mutants identified transcripts of this type of which misregulation appears to be associated with malignant growth. 

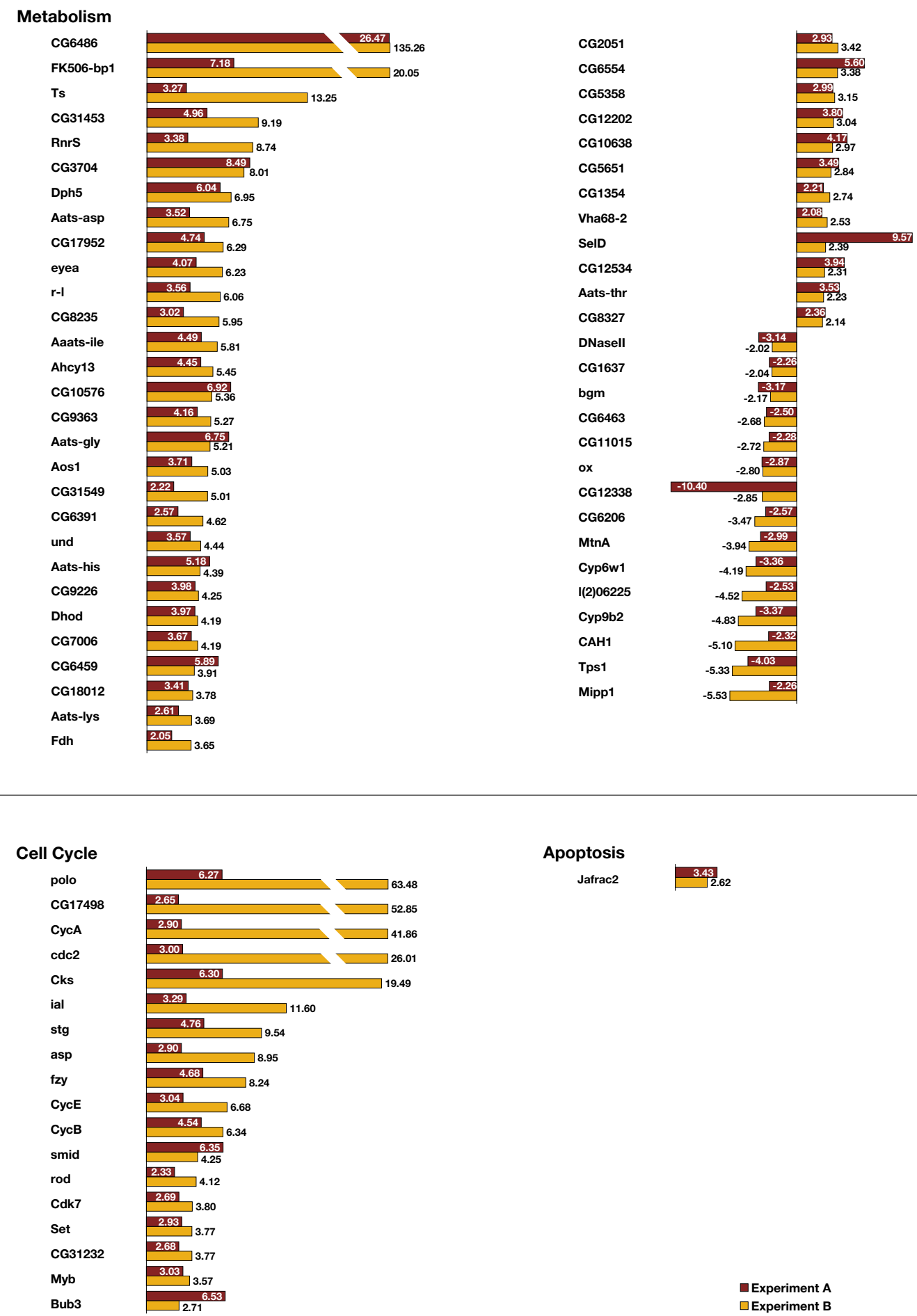

Apoptosis

Jafrac2

$\frac{3436}{3.62}$

Experiment $A$

Figure 3

Differential expression of genes belonging to the functional classes metabolism, cell cycle and apoptosis. Fold-changes for each gene are shown in red for experiment $A$ and in orange for experiment $B$, respectively. 
Among the genes involved in metabolism, we identified 41 transcripts with elevated expression levels (Figure 3). These genes included eyes absent (eya), whose activity is required for the survival of progenitor cells at a critical stage in eye morphogenesis [35] as well as uninitiated (und), the Drosophila methionine aminopeptidase 2, which was shown to be a putative regulator of translation initiation required for cell growth and patterning [36]. We also detected selenide, water dikinase (SelD) as differentially upregulated in brat ${ }^{k 06028}$ neoplasms. SelD encodes a product involved in selenocysteine biosynthesis, and mutational inactivation in SelD results in a reduction in cell proliferation in the imaginal discs and the larval brain [37]. Within the functional class metabolism, we also found 15 transcripts as significantly down-regulated in the brat ${ }^{k 06028}$ tumor condition (Figure 3). Among these were bubblegum $(\mathrm{bgm})$, encoding a product with longchain-fatty-acid-CoA-ligase activity. Mutant analysis of bgm revealed that in young homozygous mutant flies the optic lobes appear normal however as the flies grow older the optic lobes show signs of regional degeneration [38].

As expected, all of the transcripts positively regulating cell cycle showed increased expression levels in the tumor condition as compared to the wildtype situation. Among these we identified cyclin A, cyclin B, cyclin E, string (stg), $c d c 2, C d k 7, C k s$, Set, abnormal spindle (asp), fizzy (fzy), polo, and $M y b$ oncogene-like $(M y b)$. These genes are involved in the regulation of highly conserved aspects of cell proliferation such as progression through G1, S and G2/M phases, spindle orientation and the maintenance of genomic integrity throughout mitosis.

Of particular interest is the highly significant upregulation of the genes asp, fzy, rough deal (rod), and $M y b$. asp encodes a microtubule-associated protein that associates with the polar regions of the mitotic spindle. Mutants of asp are larval lethal, with a high frequency of aberrant (e.g. polyploid) cells arrested in metaphase in the larval brain, suggesting that asp may play a role in spindle pole organization during mitosis [39]. fzy encodes a product involved in cyclin catabolism and $f z y$ mutants also show metaphase arrest with compact condensed chromosomes like asp mutants [40]. rod encodes a product involved in mitotic chromosome segregation which is localised to the kinetochore, and mutations in rod result in mitotic segregational failure due to delayed or incomplete release of sister chromatids [41]. Finally $M y b$ encodes a proto-oncogene with transcriptional activator activity involved in centrosome cycle which is required to sustain the appropriate rate of proliferation, to suppress formation of supernumerary centrosomes, and to maintain genomic integrity [42].
It is noteworthy that the activity of all of these genes involved in cell cycle regulation has been linked to several aspects of neurogenesis $[43,44]$. Thus, all of these genes are known to be expressed during embryonic and larval development in mitotically active cells of the nervous system, the neuroblasts and ganglion mother cells (GMCs), suggesting that their elevated levels of transcriptional activity correlate with an elevated and aberrant activity of the cell cycle machinery in neoplasms of homozygous brat ${ }^{k 06028}$ mutants.

We did not detect any significant alteration of gene expression concerning transcripts belonging to the functional class apoptosis, except elevated expression levels for thioredoxin peroxidase 2 (Jafrac2), which is involved in the induction of apoptosis [45]. The fact that we only identified one transcript involved in programmed cell death suggests that the apoptotic program is either impaired below detectability or is unaltered in neoplastic tissue of adult brat $^{k 06028}$ mutant brain tumors.

\section{Genes involved in translation and RNA binding/processing}

Recent studies have shown that brat acts as a translational repressor [29]. Moreover, mutant analyses demonstrated that brat-mutant cells are larger than wildtype cells and have enlarged nucleoli, which are associated with an increase in total rRNA production. Also, the C. elegans homolog of brat, ncl-1, is known for being a repressor of RNA polymerase I and III transcription and for being an inhibitor of cell growth. Loss of function mutations in ncl1 , result in enlarged nucleoli. The rates of rRNA and 5S RNA transcription are increased and cells are enlarged. [46]. These data suggest that excess ribosomal synthesis and cell growth may be important aspects of the tumorous phenotype of brat ${ }^{k 06028}$ mutants [30]. Indeed, in addition to an elevated and aberrant activity of the cell cycle machinery, our gene expression profile of brat ${ }^{k 06028}$ adult brain tumors detected genes involved in all aspects of ribosome synthesis and translation control. Thus, transcript profiling of brat ${ }^{k 06028}$ mutants identified 19 transcripts as differentially expressed belonging to the functional class translation and 27 transcripts as differentially expressed in the functional class RNA binding/ processing. All of these transcripts showed increased expression level in the tumor condition as compared to the wildtype situation (Figure 4).

Among the transcripts that belong to the functional class translation we identified Eukaryotic initiation factor $1 \mathrm{~A}$ (eIF1A), Eukaryotic initiation factor 3 p40 subunit (eIF-3p40), and Int6 homologue (Int6) that encode proteins with translation initiation factor activity involved in protein biosynthesis [47]. Moreover, genes involved in translation elongation factor activity like Elongation factor $1 \alpha 48 \mathrm{D}$ (Ef1 $\alpha 48), E f 1 \gamma$, and $e E F 1 \delta$ were detected as significantly 

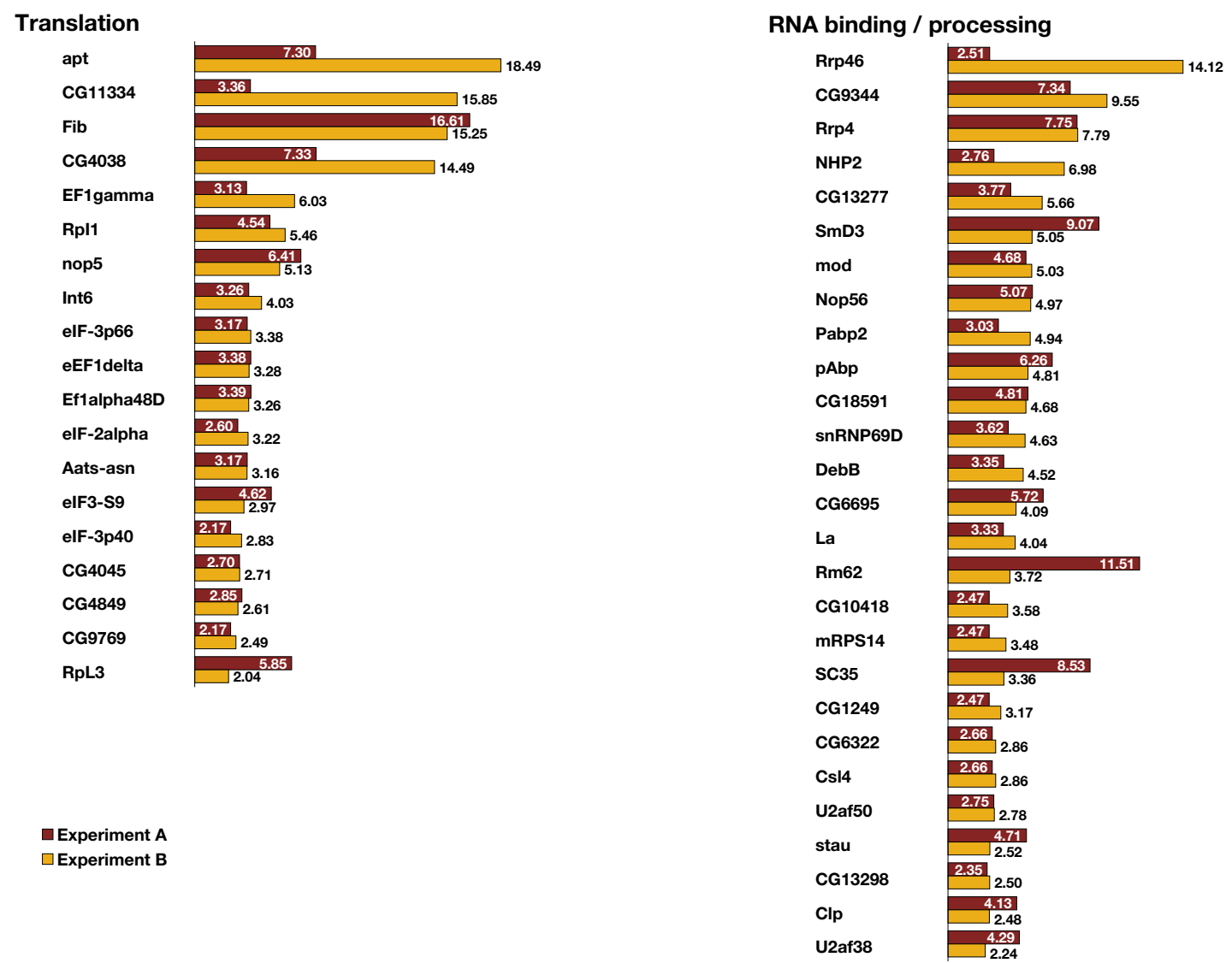

\section{Figure 4}

Differential expression of genes belonging to the functional classes translation and RNA binding / processing. Fold-changes for each individual gene are shown in red for experiment $A$ and in orange for experiment $B$, respectively.

upregulated in the tumor condition. In addition, genes involved in 35S primary transcript processing (Fibrillarin, Fib) and in rRNA processing (Nop5) were identified as upregulated. Interestingly, we also detected upregulation of Ribosomal protein L1 (RpL) and Ribosomal protein L3 (RpL3), both of which encode structural constituent of the ribosome involved in protein biosynthesis. $R p L 3$ is of particular interest as it has been mapped to the chromosomal region harbouring the Minute(3) 86D mutation [48].

Among the transcripts that belong to the functional class RNA binding/processing we identified Rrp4 and Csl4, both encoding gene products with 3'-5' exoribonuclease activity involved in mRNA processing [49]. Also Developmental embryonic $B(D e b B)$ and SC35 with pre-mRNA splicing factor activity involved in mRNA splicing were detected as significantly upregulated [50]. In addition, Rm62 encod- ing a product with ATP dependent RNA helicase activity involved in RNA interference was upregulated in the tumor condition, as were U2 small nuclear riboprotein auxiliary factor 50 (U2af50) and U2 small nuclear riboprotein auxiliary factor 38 (U2af38), both encoding products with pre-mRNA splicing factor activity involved in mRNA splicing (reviewed in [47]). Within this functional class we also identified upregulated transcripts which are involved in various aspects of cell growth and proliferation, such as polyA-binding protein ( $p A b p$ ) which encodes a product with poly(A) binding involved in positive regulation of translation. $p A b p$ mutants display cytokinesis defects, and mutant analyses demonstrated that $p A b p$ is required to connect the centrosome to the minus-ends of free microtubules (reviewed in [47]). Intriguingly, we also detected Small ribonucleoprotein Sm D3 (SmD3), which encodes a protein involved in mRNA splicing, as upregu- 
lated in the brain tumor condition. This is of particular interest since homozygous 12-day old SmD3 mutant larvae show overgrowth of the brain, hematopoietic organs and imaginal discs and die during third instar larval or pupal stages [51]. Finally, we also identified staufen (stau), which has been shown to be involved in the asymmetric localization of cell fate determinants during neuroblast divisions [52], as upregulated in neoplastic tissue.

\section{Genes involved in chromatin structure, transcription/ replication/repair, and transcriptional regulation}

In addition to the expected upregulation of genes involved in cell cycle regulation as well as ribosome synthesis and RNA processing, we also observed that the basal transcriptional machinery was significantly upregulated in the brat ${ }^{k 06028}$ tumor condition (Figure 5). Within the functional class chromatin structure we found 13 genes with elevated expression levels. Among those are genes involved in various aspects of chromatin modeling such as Nucleoplasmin (Nlp), involved in nucleosome spacing, and Nucleosome assembly protein 1 (Nap1) as well as Chromatin assembly factor 1 subunit (Caf1), both encoding proteins with histone-specific chaperone activity [53]. We also detected two suppressors of variegation, namely Suppressor of variegation 3-9 (Su(var)3-9) with histone methyltransferase activity [54] and Suppressor of variegation 205 (Su(var)205) involved in the establishment of chromatin silencing. Interestingly, mutant analysis of Su(var)205 revealed that larval brain neuroblasts show cytokinesis defects during mitosis [54]; this is also the case for gluon $(g l u)$, which we detected as significantly upregulated in the tumor condition. In glu mutants, larval brain neuroblasts show distinct abnormalities during chromosome segregation and lethality occurs during the late larval stage [55].

In the functional class transcription/replication/repair we identified 20 genes as differentially regulated in the bratk06028 tumor condition, all of them having elevated expression levels as compared to wildtype. Among them are the minichromosome maintenance (MCM) genes, which encode an evolutionary conserved family of molecules that form an important part of the pre-replicative complex, required for DNA replication [56]. We found two members of this complex ( $\mathrm{mcm} 2$ and $\mathrm{mcm} 3$ ) as upregulated in brat ${ }^{k 06028}$ neoplasms. Interestingly, Mcm2 mutants persist as third instar larvae for several days, and dissection of wandering larvae demonstrates that their CNS is smaller than that of wildtype and that they lack identifiable imaginal discs [57]. We also detected mutagen-sensitive 209 (mus209), involved in mitotic spindle assembly as upregulated. Mutants of mus209 show abnormal chromosome condensation [58], whereas mutations of rad50, a gene involved in DNA repair, result in elevated levels of anaphase bridges in dividing cells of third instar larval brain and imaginal discs. Moreover, RNA polymerase II $15 \mathrm{kD}$ subunit (RpII15), involved in transcription from Pol II promoter [59] and absent, small or homeotic disc 2 (ash2), a member of the trithorax group were detected as upregulated. Interestingly, mutant alleles for ash2 are larval pupal lethals and display imaginal disc and brain abnormalities [60].

Among the transcripts belonging to the functional class transcriptional regulation, we identified two members of the snail family of zinc-finger transcription factors, namely worniu (wor) and snail (sna) as significantly upregulated in brat $^{k 06028}$ neoplasms. During wildtype embryogenesis, both genes are expressed during neuroblast delamination, and mutant analyses suggest that Snail and Worniu function in neuroblasts, around the time of division to give rise to ganglion mother cells (GMCs) [61]. Moreover, we also detected upregulation of several other transcription factors involved in the control of proliferative activity of embryonic and postembryonic neuroblasts. Thus, we identified tailless (tll), deadpan (dpn), and castor (cas) as upregulated. $t l l$ is expressed in procephalic neuroblasts and required for their specification as tll mutants lack the anterior brain [62]. dpn encodes a pan-neural gene shown to be expressed in all neuronal lineages during embryogenesis as well as in neuroblasts of the larval CNS and in precursors of sensory neurons in imaginal discs. Loss- and gain-of-function experiments suggest that $d p n$ activity is critical for the proper regulation of cell proliferation in the larval brain [63]. cas is involved in a cascade of sequentially expressed transcription factors, which translates information on timing of GMC formation [64]. In addition, cas is known to be involved in post-embryonic brain development as small homozygous somatic mutant cas clones in the adult brain lead to ellipsoid body and mushroom body defects [65]. Finally, we also detected diminutive $(\mathrm{dm})$, the Drosophila homolog of the proto-oncogene c-myc, as significantly upregulated in the brat ${ }^{k 06028}$ tumor condition. M $M y c$ genes link patterning signals to cell division by regulating primary targets involved in cellular growth and metabolism [66].

\section{Genes involved in cytoskeleton/structural and signal transduction}

In previous studies, histological analysis of brat ${ }^{k 06028}$ mutants indicated that the brain tumor phenotype is primarily due to uncontrolled divisions of optic lobe neuroblasts and GMCs [33]. Our microarray expression analysis supports the assumption that neuroblasts and/or GMCs are at the cellular origin of these brain tumors. This is not only evident by the significant upregulation of genes involved in neuroblast delamination and proliferation such as wor, sna, tll, $d p n$, and cas, but also by the elevated transcription levels of specific genes belong- 


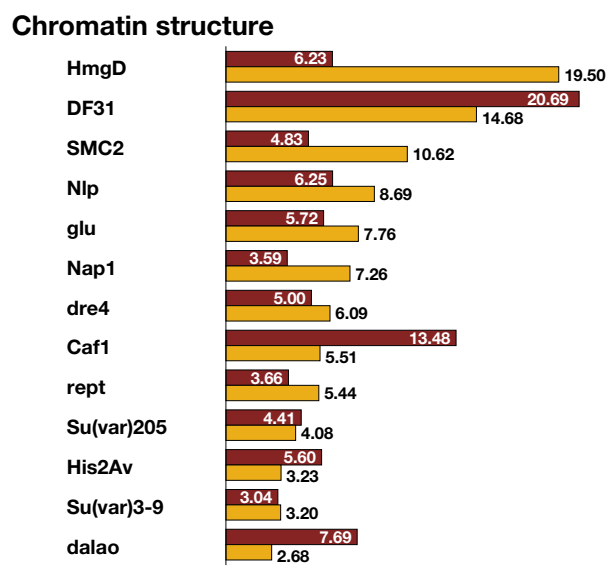

Transcriptional regulation

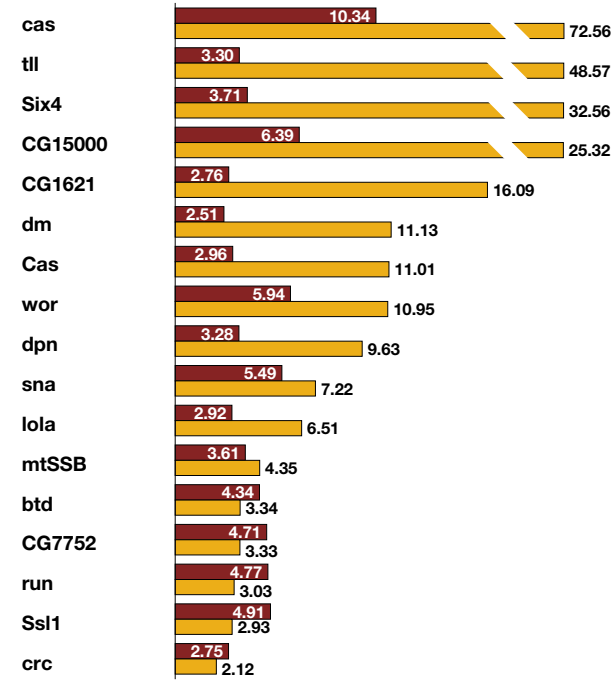

\begin{tabular}{|c|c|}
\hline \multicolumn{2}{|c|}{ Transcription / Replication / Repair } \\
\hline Mcm2 & 3.17 \\
\hline mus209 & - 26.57 \\
\hline RnrL & 5.38 \\
\hline UTPase & 9.81 \\
\hline Mcm3 & 17.86 \\
\hline CG8142 & $\square 11.50$ \\
\hline CG15220 & $8.01 \square 10.34$ \\
\hline CG9273 & 10.30 \\
\hline ash2 & $5.72 \square-8.87$ \\
\hline Rrp1 & $5.12 \square 8.80$ \\
\hline rad50 & 5.03 \\
\hline CG9135 & 4.63 \\
\hline mus210 & $4.13 \square 6.90$ \\
\hline $\mathrm{RfC} 40$ & $4.39 \square 6.78$ \\
\hline RpA-70 & ${ }_{4.42}^{4.34}$ \\
\hline CG6258 & \begin{tabular}{|ll}
2.95 & \\
\end{tabular} \\
\hline Bap60 & $\begin{array}{l}3.56 \\
2.90\end{array}$ \\
\hline Ercc1 & 2.58 \\
\hline Rpb8 & $2.800_{2.77}$ \\
\hline Rpll15 & 2.64 .19 \\
\hline
\end{tabular}

Experiment A $\square$ Experiment B

\section{Figure 5}

Differential expression of genes belonging to the functional classes chromatin structure, transcription / replication / repair, and transcriptional regulation. Fold-changes for each gene are shown in red for experiment $A$ and in orange for experiment $B$, respectively. 

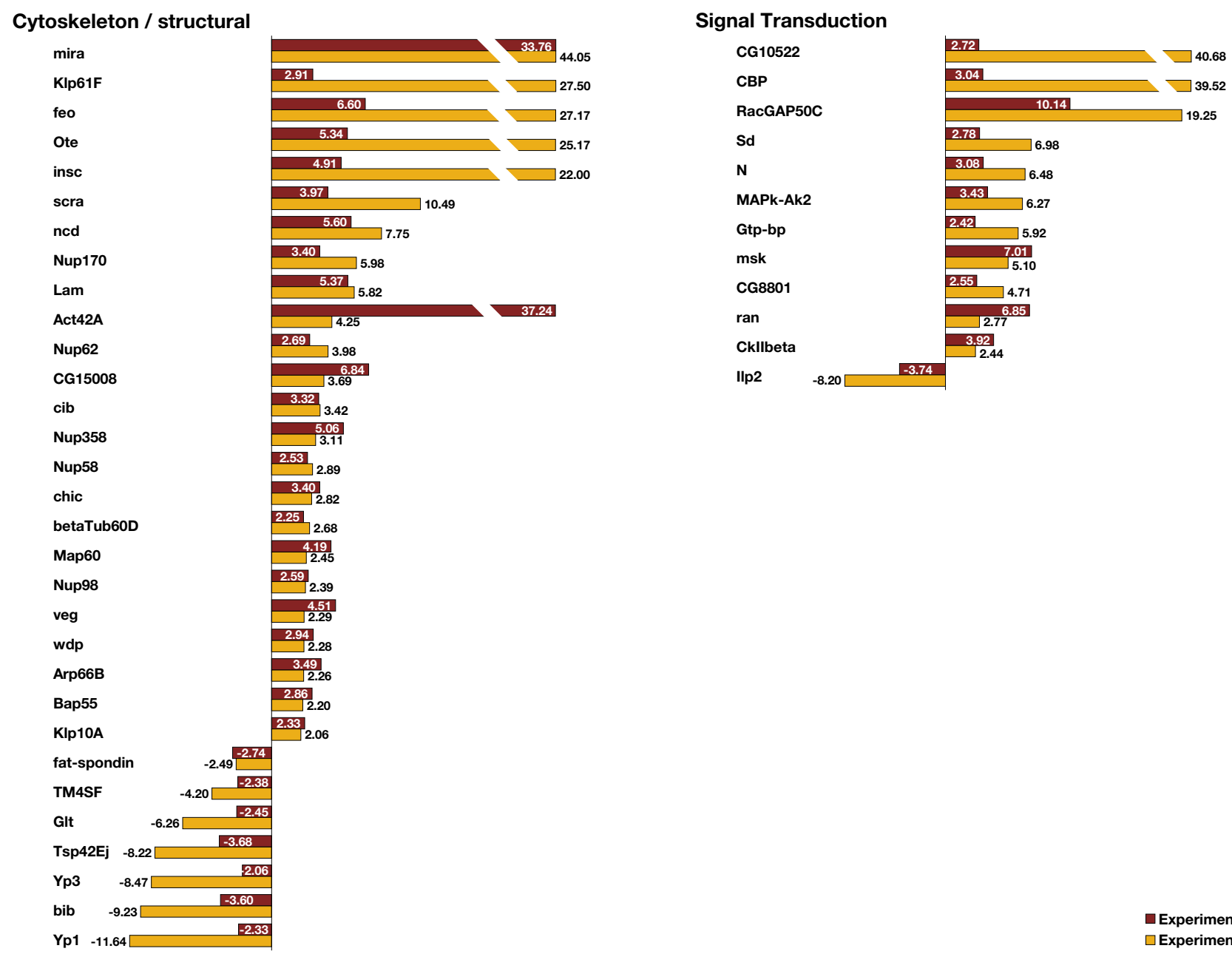

$\square$ Experiment A
$\square$ Experiment B

Figure 6

Differential expression of genes belonging to the functional classes cytoskeletal / structural and signal transduction. Foldchanges for each gene are shown in red for experiment $A$ and in orange for experiment $B$, respectively.

ing to the functional classes cytoskeleton/structural and signal transduction (Figure 6).

In the functional class cytoskeleton/structural, we found high levels of transcription in brat ${ }^{k 06028}$ tumorous tissue for the genes miranda (mira) and inscuteable (insc). This is of particular interest, since both proteins play essential roles in the asymmetric localization of cell fate determinants during neuroblast divisions. Miranda creates intrinsic differences between sibling cells by mediating the asymmetric segregation of transcription factor Prospero into only one daughter cell during neural stem-cell division. In insc mutants, mitotic spindles in neuroblasts fail to rotate into proper position and neuroblasts divide in random orientation resulting in general disorganization of the neuroblast array and defective neuroblast morphology (reviewed in [67]). Moreover, we also identified as significantly upregulated in the tumor condition ciboulot (cib), an actin binding protein, and the Drosophila profilin protein chickadee (chic), both of which cooperate in central brain metamorphosis [68]. Intriguingly, expression of big brain (bib) appears to be downregulated in the brat ${ }^{k 06028}$ tumor condition. bib encodes a product with connexon channel activity, which is required autonomously in epidermal precursors to prevent neural development (reviewed in [69]). 
Among those transcripts belonging to the functional class signal transduction, we identified several members of GTPase signal transduction pathways as significantly upregulated in brat ${ }^{k 06028}$ neoplasms. Thus, we identified RacGAP50C, which has GTPase activator activity and is involved in Rho protein signal transduction, and also three members of the Ran GTPase signal transduction pathway, namely Segregation distorter $(S d)$, ran, and moleskin (msk). Moleskin, for example, appears to be involved in EGF receptor signalling pathway initiation of gene expression in response to Drosophila receptor tyrosine kinase signalling [70]. We also detected MAP kinase activated protein-kinase-2 (MAPk-Ak2), which has protein serine/threonine kinase activity, as significantly upregulated. In addition, we identified Notch $(N)$ as significantly upregulated in the bratk06028 tumor condition. Notch encodes a transmembrane receptor mediating cell-cell communication, and Notch signalling has been implicated in a wide variety of cellular processes, including the maintenance of stem cells, specification of cell fate, differentiation, and proliferation [71]. Surprisingly, however, the Insulin-related peptide (Ilp2), a component of the insulin signalling pathway, was downregulated in the tumor condition. Overexpression of Ilp2 alters growth control in a Insulin receptor-dependent manner, suggesting a role for Ilp2 in controlling organismal size by augmenting both cell number and cell size of different organs (reviewed in [66]).

\section{Genes involved in cell surface receptors/CAMs, chaperones, proteolytic systems, stress response and transport}

Previous studies have shown that tumor cells derived from homozygous brat larval brain tissue can grow not only in situ, but also after transplantation into adult host flies. The transplanted cells grow rapidly, forming metastases and secondary malignant tumors that finally kill their host [34]. This suggests that loss of brat leads to the acquisition of invasive and metastatic properties of the resulting tumor cells. This acquisition of invasive and metastatic abilities is associated with altered binding specificities of cell adhesion molecules (CAMs), the activation of proteases, as well as chaperones and heat shock proteins mediating stress response [1,72]. In accordance with this, our transcriptional analysis of brat $^{k 06028}$ tumor cells identified genes as differentially regulated in the tumor condition belonging to the functional classes cell surface receptors/CAMs, chaperones, proteolytic systems, and stress response (Figure 7). Within the class cell surface receptors/CAMs we identified Neurotactin (Nrt), a transmembrane protein that localizes to cell-cell junctions where it mediates cell adhesion and cell signalling, as upregulated [73]. Three other genes belonging to the class cell surface receptors/CAMs were differentially downregulated in the brat ${ }^{k 06028}$ tumor condition. Among the classes proteolytic systems, chaperones and stress response, we identified genes upregulated like Ubiquitin carboxy-terminal hydrolase (Uch), involved in protein deubiquitination, and granny smith with leucyl aminopeptidase activity. Also the chaperones T-complex Chaperonin 5 (Cct5) and Cctgamma with chaperonin ATPase activity involved in protein folding and the heat shock proteins Hsp27, Hsp26, and $H s c 70-4$ were identified as significantly upregulated in the brat ${ }^{k 06028}$ tumor condition. Finally, we detected 10 transcripts belonging to the functional class transport as differentially regulated in neoplastic brat ${ }^{k 06028}$ tissue. Among these is Pendulin (Pen), an adaptor molecule which is expressed in embryonic neuroblasts and the proliferating regions of the larval brain lobes and may be required for the normal transmission and function of proliferative signals in the cells [74].

\section{Vertebrate homologs of genes differentially regulated in brat ${ }^{\mathrm{k} 06028}$ neoplasms are involved in mammalian cancer formation}

Our analysis of the 321 genes differentially regulated in brat $^{k 06028}$ neoplasms revealed genes involved in general aspects of tumorigenesis such as elevated and aberrant metabolic activity, elevated and aberrant activity of the cell cycle and basal transcriptional machinery, as well as elevated and aberrant activity of ribosome synthesis and translation control. Considering the level of gene and pathway conservation, the similarity of cellular processes, and the emerging evidence of functional conservation of Drosophila genes that are homologous to mammalian oncogenes or tumor suppressor genes [16,17], we wondered whether our data might reveal any parallels to the genetic alterations associated with mammalian cancer formation. This is of particular interest since one of the two human homologs of brat, TRIM3, has been mapped to chromosome 11 p15 [75,76], a region that has been termed the "multiple tumor-associated chromosomal region 1 " due to the presence of numerous cancer-related genes in this region $[77,78]$.

We therefore searched available databases in order to identify vertebrate homologs of the 321 genes differentially regulated in brat ${ }^{k 06028}$ neoplasms and to determine their possible involvement in mammalian cancer formation. We identified 62 out of 321 Drosophila genes as having mammalian homologs, of which misregulation has been associated with various types of tumors (see Table 2). Mammalian homologs of genes involved in the regulation of conserved aspects of cell proliferation were found to be implicated in mammalian cancer formation. Among these are mammalian homologs of cyclins, Cdks, and genes involved in various other aspects of cytokinesis and the maintenance of genomic integrity. Thus, the string homolog $C d c 25 B$, encoding a dual-specific phosphatase that mediates cell cycle progression by activating cyclin- 

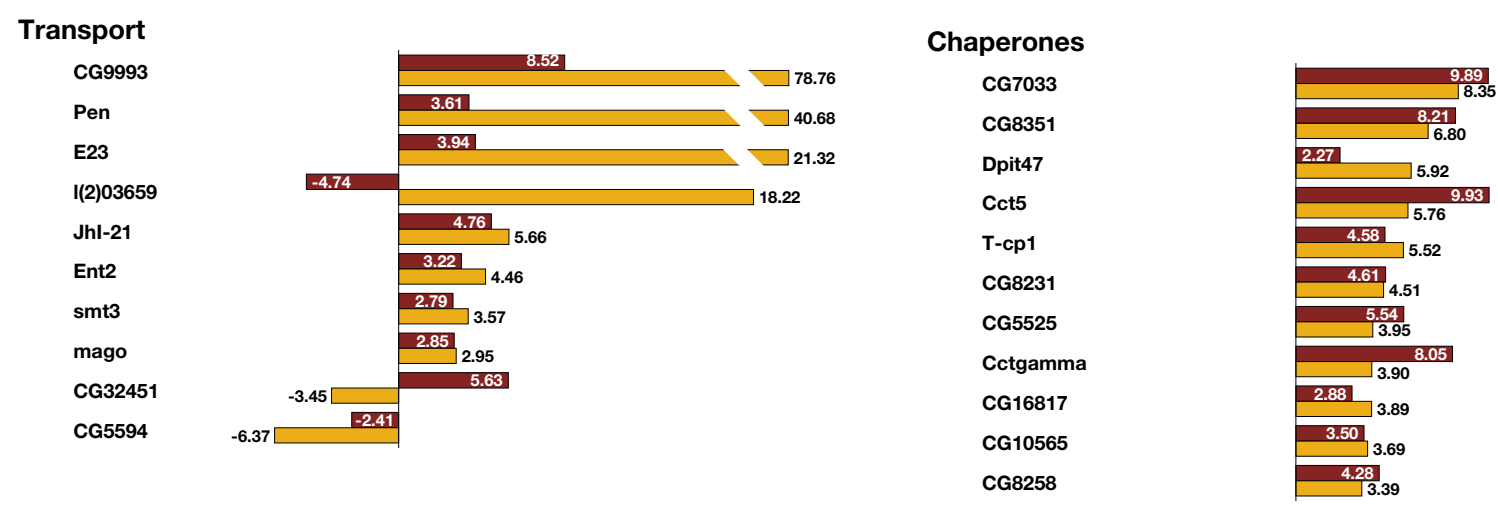

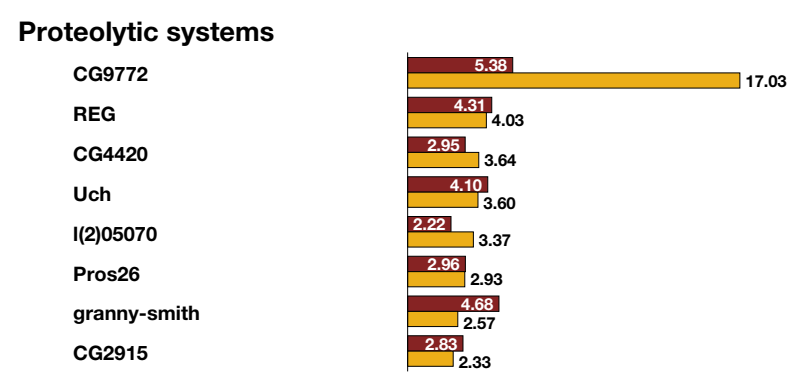
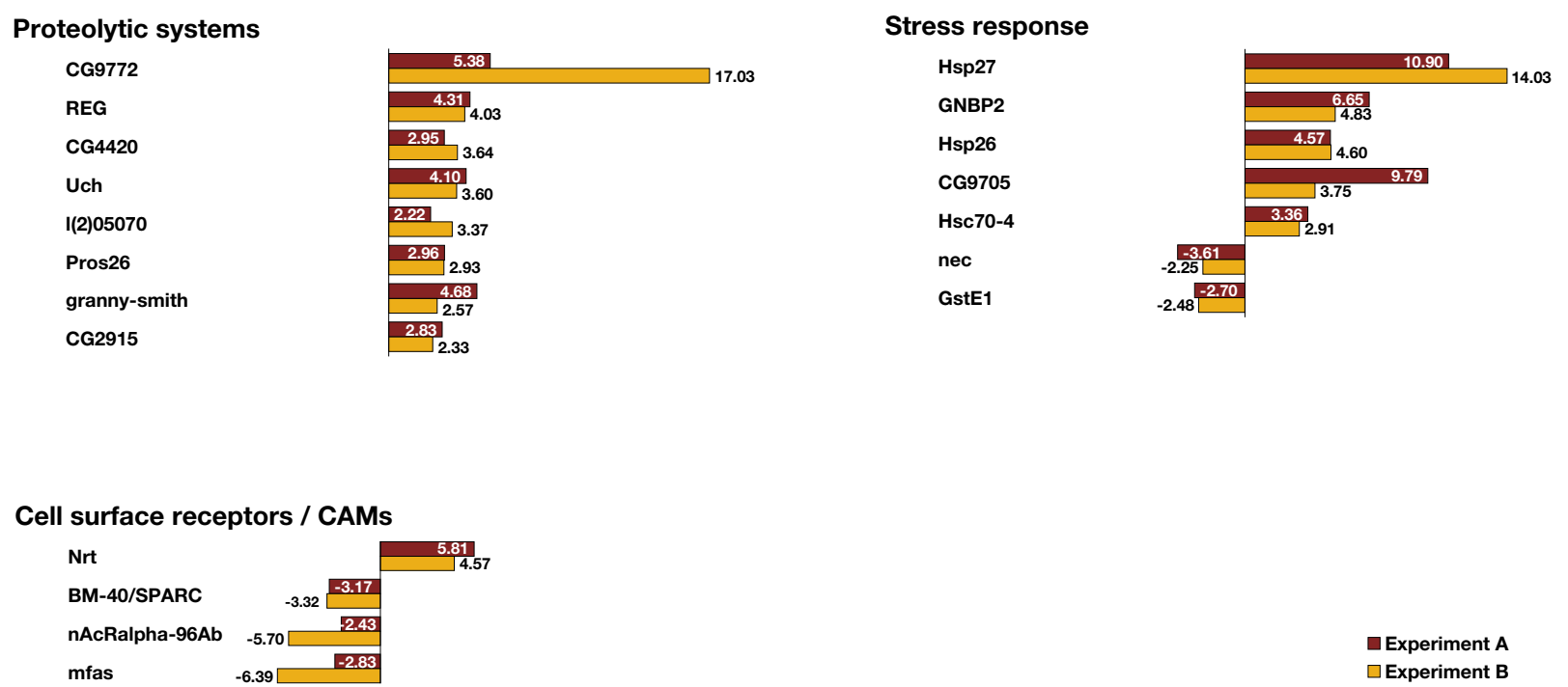

Experiment A

Figure 7

Differential expression of genes belonging to the functional classes cell surface receptors /CAMs, chaperones, proteolytic systems, stress response, and transport. Fold-changes for each gene are shown in red for experiment $A$ and in orange for experiment $B$, respectively.

dependent kinases, has been shown to possess oncogenic potential and is frequently overexpressed in human prostate cancer tissues [79]. Drosophila CG9993 encodes for a long-chain fatty acid transporter and its rat homolog (FATP) shows elevated transcript levels in hepatoma cell lines [80]. Homologs of Drosophila MCM family of proteins are known as proliferation markers in vertebrates, and evidence exists that HsMCM2 is upregulated in primary human tumor tissue [81]. Furthermore, it has been shown that the rate and level of Mcm3 and MCM4 expres- 

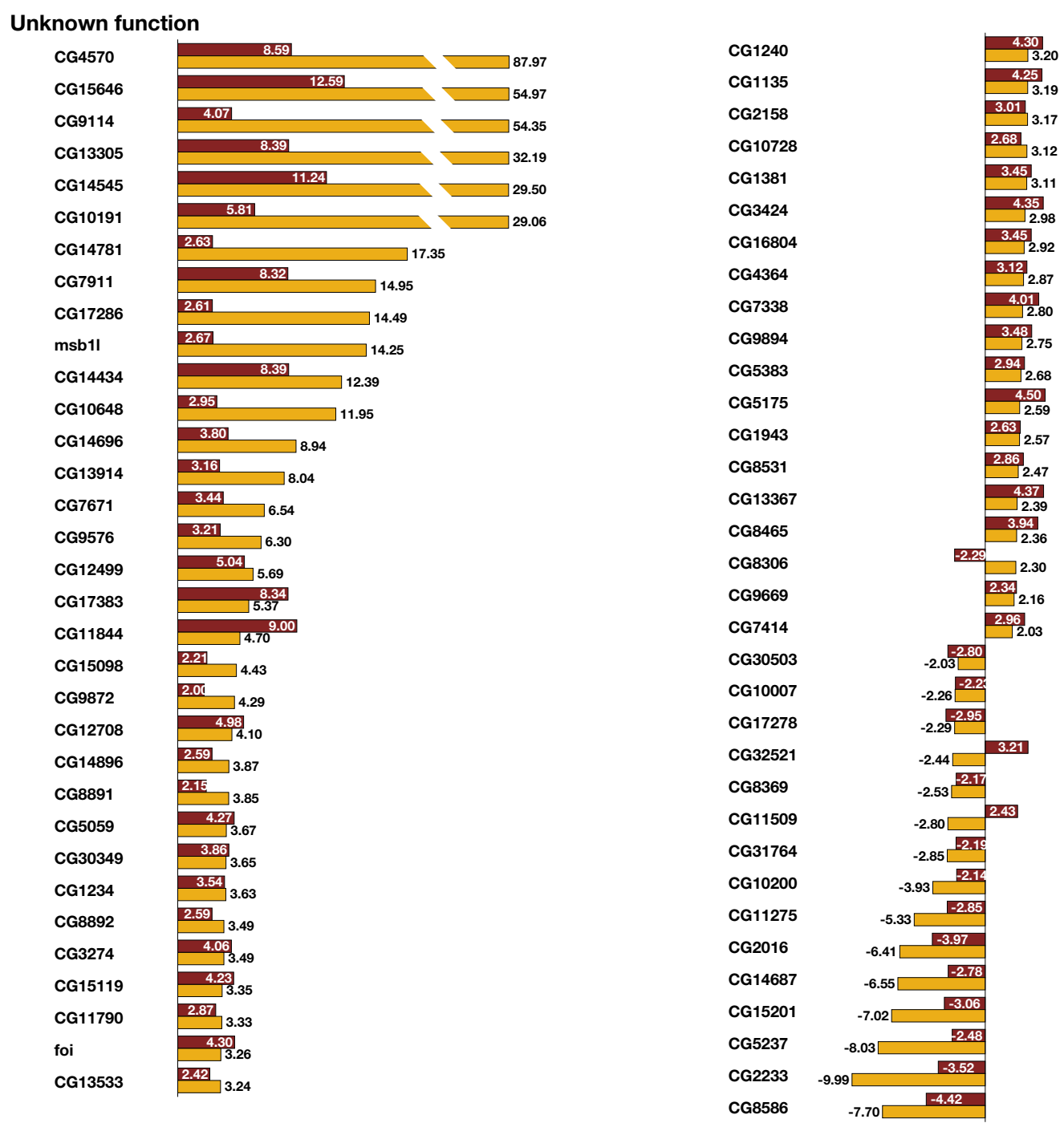

Experiment A

$\square$ Experiment B

Figure 8

Differential expression of genes belonging to the functional class unknown function. Fold-changes for each gene are shown in red for experiment $A$ and in orange for experiment $B$, respectively.

sion appears to be higher in cancer cells than in normal proliferating cells of the uterine cervix and dysplastic cells.

Prominent examples of genes involved in mammalian cancer formation are the proto-oncogenes $M y b$ and $M y c$. The $M \gamma c$ gene is a central regulator of proliferation, differ- entiation, cell survival, and neoplastic transformation. It is found mutated or overexpressed in up to $30 \%$ of human cancers and the Myc network appears to regulate a large number of genes, approaching $10 \%$ of human genes [82]. Similarly, the human homolog of Drosophila CG9772, called $S C F S k 2$, is an ubiquitin ligase encoding onco-pro- 
Table 2: Drosophila genes differentially regulated in brat ${ }^{\mathrm{k0} 628}$ neoplastic tissue and their mammalian homologs shown to be involved in cancer formation.

\begin{tabular}{|c|c|c|}
\hline Fly gene & Mammalian homolog & Cancertype \\
\hline CGI 7498 & HsMAD2LI & breast cancer \\
\hline CycE & $\mathrm{HsCCNEI}$ & breast cancer \\
\hline MAPk-Ak2 & HsMAPKAPK2 & breast cancer \\
\hline Ent2 & HsSLC29AI & breast cancer \\
\hline CG6546 & HsBAF53A & breast cancer \\
\hline FK506-bpl & HsFK506-bpl & childhood astrocytoma \\
\hline$c i b$ & HsTMSB4X & colon cancer \\
\hline UTPase & HsDUT & colorectal \\
\hline Eflgamma & HsEEFIG & colorectal adenoma \\
\hline Aats-ile & HsIARS & colorectal cancer \\
\hline msk & HsIPO7 & colorectal cancer \\
\hline CG8235 & HsSCYEI & fibrosarcoma, melanoma \\
\hline Bub3 & HsBUB3 & gastric cancer \\
\hline Myb & MmMYB & glioma \\
\hline CG5525 & $\mathrm{HsCCT} 4$ & hepatocelluar and colonic carcinoma \\
\hline$c d c 2$ & $\mathrm{HsCDC2}$ & hepatocellular cancer \\
\hline Lam & HsLMNBI & hepatocellular cancer \\
\hline CG9993 & MmFATP & hepatoma 7288 CTC \\
\hline CG3/232 & $\mathrm{HsCCNK}$ & Karposi sarcoma \\
\hline Aats-his & HsHARS & laryngeal epithelial carcinoma \\
\hline $\operatorname{ash} 2$ & HsASH2L & leukemia \\
\hline und & HsMetAP2 & leukemia \\
\hline$G T P-b p$ & $H_{s} S R P R$ & leukemia \\
\hline$N$ & HsNotch2 & lung cancer, leukemia \\
\hline Dpit47 & HsTTC4 & melanoma \\
\hline nop5 & $H_{s} \mathrm{NOP} 5 / \mathrm{NOP} 58$ & melanoma \\
\hline btd & $H s$ EGR I & melanoma, prostate cancer \\
\hline Jafrac2 & HsPRDX4 & mesothelioma \\
\hline Nup98 & HsNUP98 & myeloid leukemia \\
\hline Rm62 & HsDDX5 & ovarian cancer \\
\hline$f z y$ & $\mathrm{HsCDC20}$ & pancreatic cancer \\
\hline mfas & HsTGFBI & pancreatic cancer \\
\hline CGI5000 & $H s \mathrm{NABI}$ & prostate cancer \\
\hline Hsp27 & $\mathrm{HsHSPB} 2$ & prostate cancer \\
\hline CG8/42 & $\mathrm{HsRFC}_{\mathrm{s}}$ & prostate cancer \\
\hline ran & HsRAN & prostate cancer \\
\hline Eflalpha48D & HsEEFIAI & prostate cancer \\
\hline tll & $M m N r 2 f l$ & retinoblastoma \\
\hline Erccl & $\mathrm{HsERCCl}$ & squamous cell carcinoma of the head and neck \\
\hline Ckllbeta & $\mathrm{H}_{s} \mathrm{CSNK} 2 \mathrm{~B}$ & squamous cell carcinoma of the head and neck \\
\hline GstEI & HsGSTTI & thyroid cancer \\
\hline Mippl & HsMINPPI & thyroid cancer \\
\hline CG9344 & HsSNRPF & uterine cancer \\
\hline RnrS & HsRRM2 & uterine cancer \\
\hline SmD3 & HsSNRPD3 & uterine cancer \\
\hline Mcm3 & $\mathrm{HsMCM} 3$ & uterine cervical carcinoma \\
\hline polo & HsPLK & various \\
\hline Cyclin A & $\mathrm{HsCCNAI}_{s}$ & various \\
\hline $\mathrm{Mcm} 2$ & $\mathrm{HsMCM} 2$ & various \\
\hline KIp6IF & HsKIFII & various \\
\hline mus209 & HsPCNA & various \\
\hline CG9772 & HsSKP2 & various \\
\hline Fib & $H s \mathrm{FBL}$ & various \\
\hline stg & $\mathrm{HsCDC}_{s} 25 \mathrm{~B}$ & various \\
\hline
\end{tabular}


Table 2: Drosophila genes differentially regulated in brat ${ }^{\mathbf{0 6 0 2 8}}$ neoplastic tissue and their mammalian homologs shown to be involved in cancer formation. (Continued)

\begin{tabular}{lll}
\hline CycB & & \\
Cdk7 & HsCCNBI & various \\
eEFIdelta & HsCDK7 & various \\
crc & HsEEFID & various \\
CG8586 & HsATF4 & various \\
betaTub60D & HsKLKBI & various \\
BM-40/SPARC & HsTUBB2 & various \\
dm & HsSPARC & various \\
& HsMYC & various
\end{tabular}

Drosophila genes differentially regulated in brat ${ }^{k 06028}$ neoplastic tissue and their mammalian homologs shown to be involved in cancer formation. Indicated are the Drosophila genes, their human (Homo sapiens, Hs) or mouse (Mus musculus, Mm) homolog, and the cancer type for which misregulation of the mammalian homolog has been reported in available databases like Flybase and PubMed. References are given in the supplementary material (References for table 2) [see Additional file 5].

tein that is one of the components of the machinery used to control Myc levels through the ubiquitin pathway. Interestingly, this ubiquitin ligase is also required for induction of Myc-responsive genes, suggesting that ubiquitination not only promotes Myc turnover but also "licenses" its transcriptional activity [83]. Examples of homologous genes involved in human brain tumor formation are the tailless ortholog $\mathrm{Nr} 2 \mathrm{f} 1$ involved in retinoblastoma, and the homologs of $M y b$ (MYB), dm (MYC), and Notch (NOTCH2), whose misregulation has been associated with human gliomas [71,84].

\section{Discussion \\ A core transcriptional signature of neoplastic brain tissue in Drosophila}

In order to gain insights into the transcriptional alterations associated with brain tumors in vivo, we have determined the transcriptional signature of an adult brain tumor in Drosophila caused by homozygous mutation in the tumor suppressor gene brat. To this end, we have conducted two independent genome-wide gene expression studies using two different oligonucleotide microarray platforms to compare adult wildtype flies with flies displaying the adult brat ${ }^{k 06028}$ mutant brain tumor. Crossvalidation of our comparative analysis of adult wildtype heads compared to brat ${ }^{k 06028}$ heads versus dissected brat ${ }^{206028}$ brains compared to dissected adult brains of flies generated by transposon excision of the brat ${ }^{k 06028}$ P-element identified a core transcriptional signature of brat ${ }^{k 06028}$ neoplastic tissue. The obtained transcriptional signature revealed genetic alterations associated with malignant growth in a highly reproducible manner, despite the fact that both the biological material and the array platforms used differed considerably between the two experiments. This involved the use of stringent filter criteria such as a significance value of $\mathrm{p} \leq 0.0001$ ( $\mathrm{t}$-test). Due to these very stringent filter criteria, the 321 transcripts detected as differentially regulated in the brat ${ }^{k 06028}$ tumor condition probably represent only a subset of genes that could be involved in brain tumorigenesis. For example, it has been shown that PTEN plays a crucial role in the highly conserved insulin/PI3-kinase (PI3K) signaling pathway involved in cell growth and proliferation (for review see [66] and the human homolog of PTEN is frequently lost in gliomas (reviewed in [84]). Although we did detect PTEN as differentially down-regulated in the brat tumor condition in both experiments, it was not incorporated into the core set of genes differentially regulated in brat ${ }^{k 06028}$ neoplasms due to p-values below our cutoff value (see supplementary material).

Nevertheless, our genome-wide microarray analysis in Drosophila identified characteristic features of malignant growth such as those found in human cancer. Thus, we detected gene expression changes indicative of elevated and aberrant metabolic activity, elevated and aberrant activity of the cell cycle and basal transcriptional machinery, and elevated and aberrant activity of ribosome synthesis and translation control associated with the adult brat ${ }^{k 06028}$ mutant brain tumor. Our data are in accordance with assumptions that the vast catalog of cancer cell genotypes is a manifestation of essential alterations in cell physiology that collectively dictate malignant growth: self-sufficiency in growth signals, insensitivity to growthinhibitory (antigrowth) signals, evasion of programmed cell death (apoptosis), limitless replicative potential, and tissue invasion and metastasis [1]. This is further exemplified by the fact that for $20 \%$ of the genes differentially regulated in the Drosophila brat ${ }^{k 06028}$ tumor condition it was possible to identify mammalian homologs associated with various types of tumors. These include homologs of $M \gamma b, M \gamma c$, cyclins as well as other genes involved in cell growth and proliferation control whose misregulation is frequently associated with mammalian cancer formation and malignant growth [1].

\section{Brat acts as a tumor suppressor during Drosophila brain development}

Brat was originally identified as a growth suppressor of the larval brain of Drosophila, with mutant brains growing up 
to eightfold larger than normal $[28,32]$. Loss of brat also conferred metastatic potential upon tissues transplanted into wildtype host flies [34]. Moreover, our analysis of the brat ${ }^{206028}$ allele shows that a substantial amount $(15 \%)$ of homozygous mutant flies eclose and show a strong neoplastic adult brain phenotype with 100\% penetrance. These data demonstrate that Brat functions as a tumor suppressor during brain development of Drosophila.

In general, tumor suppressors act as molecular antagonists to the formation of malignancy, a physiological state that is characterized by indefinite cellular growth and division [1]. This in turn requires elevated levels of transcriptional activity of genes involved in all aspects of aberrant cell cycle activity. Indeed, our genome-wide microarray expression analysis of brat ${ }^{k 06028}$ neoplastic tissue revealed genetic alterations that can be attributed to malignant growth. We identified essential components of the cell cycle machinery like cyclin $A, B, E$, string and $M y b$ as significantly upregulated in the tumor condition. This elevated cell cycle activity is accompanied by significant upregulation of genes involved in DNA replication, chromatin structure and cytokinesis, such as gluon, Mcm2 and Mcm3, and the Drosophila $M y c$ homolog diminutive. Gain of function of these genes is frequently associated with malignant overgrowth and cancer in Drosophila [16]. Moreover, deregulation of the proto-oncogenes $M y b$ and $M y c$ characterizes one of the hallmarks of cancer, as the oncogenic activity of these genes in turn impairs differentiation and promotes growth [66]. In addition, we also observed significant upregulation of the Ran GTPase pathway since three members of it, namely $S d$, ran, and $m s k$, show elevated expression levels in the brat ${ }^{k 06028}$ tumor condition. Recent data suggest that Ran GTPase signalling serves as a positional marker for the eukaryotic genome throughout the cell cycle by regulating microtubule nucleation and nuclear envelope formation around chromatin (reviewed in [85]). This together with the elevated and aberrant activity of several other structural components required for proliferation and cytokinesis emphasises the self-sufficiency of the cellular machinery during unrestrained growth.

\section{Proliferation control via ribosome synthesis regulation by brat?}

Recent results demonstrate that brat functions to repress ribosomal RNA synthesis and cell growth. brat mutant cells are larger than control cells, have enlarged nucleoli and contain excess rRNA. Furthermore, brat overexpression inhibits clone and organ growth, and leads to a decreased level of rRNA per cell [30]. Based on these observations it has been suggested, that in contrast to the cell growth regulation pathway of the insulin receptor and its effectors, brat affects cell growth not through the activity of ribosomes, but rather through the regulation of their synthesis [30]. Indeed, disruption of one or more of the steps that control protein synthesis has been associated with alterations in the cell cycle and regulation of cell growth. For example mutations that inactivate the tumorsuppressor activity of $R B$ or $p 53$, or both, result in aberrant upregulation of essential components in the protein synthesis machinery and increase ribosome biogenesis, leading to enhanced mRNA translation rates (reviewed in [86]). Among the 321 genes differentially regulated due to loss of the tumor suppressor activity of brat, we identified several genes involved in ribosome biogenesis and RNA processing as significantly upregulated in neoplastic tissue. One of the most prominent examples is ribosomal protein RpL3 which maps to the chromosomal region harbouring the Minute(3) 86D mutation [48]. However, although we observe several genes involved in protein synthesis and ribosome biogenesis as differentially upregulated in the brat ${ }^{k 06028}$ tumor condition, it remains to be determined whether these phenomena represent the cause or consequence of tumor formation.

\section{Neuroblast polarity and asymmetric division}

Interestingly, we find that inscuteable (insc), staufen (stau), snail (sna), miranda (mira), and worniu (wor) have elevated transcript levels in brat ${ }^{k 06028}$ brain tissue. Both insc and stau are involved in asymmetric segregation of cell fate determinants in dividing neuroblasts and insc expression is thought to be regulated by sna $[52,61]$. Miranda is an adaptor protein involved in the distrinution of the Prospero gene product. Prospero is required to distinguish the proliferative capabilities of NBs and GMCs [67]. As it is known that the Discs large (Dlg), Scribble (Scrib) and Lethal giant larvae $(\mathrm{Lgl})$ tumor suppressor proteins regulate multiple aspects of neuroblast asymmetric cell division these findings strengthen the link between tumorigenesis and asymmetry in cell division [87].

\section{Conclusions}

Taken together, our genome-wide microarray expression analysis of an adult brain tumor in Drosophila caused by mutation in the tumor suppressor gene brat identifies a core set of genes whose deregulation can be attributed to the genetic alterations associated with tumor formation and malignant growth. We detect aberrant and elevated activity in the transcription of genes involved in metabolic activity, cell cycle regulation, cytokinesis, as well as in basal transcriptional regulation. $20 \%$ of the genes we identified as differentially regulated in the bratk06028 tumor condition have mammalian homologs whose misregulation has been associated with various types of tumors. Moreover, we observed significant alterations in transcriptional activity of genes involved in ribosome biogenesis, translation and RNA processing due to loss of the translational repressor encoded by brat. This may indicate that loss of brat leads to overexpression of ribosomal pro- 
teins and increased ribosome function, which in turn may cause malignant growth. Considering the evolutionary conservation of gene structure and function, we propose that our results obtained by the first genome-wide expression analysis of an adult brain tumor in Drosophila will also be valid for tumor formation in mammals. It will now be important to elucidate at the cellular and molecular level the mechanisms involved in the genetic alterations caused by mutation of the tumor suppressor brat, which ultimately lead to tumor formation, metastasis and invasiveness.

\section{Methods}

\section{Fly strains and genetics}

The wildtype was Oregon $\mathrm{R}$. The brat allele used in this study is bratk06028, balanced over $C \gamma O, P\left\{w^{+m c}=\right.$ ActGFP J JMR1. Flies used for histology and for transcript profiling were 1 to 2 days old homozygous $P\left\{w^{+m c}=l a c W\right\}$, bratk06028 males and females, identified by the absence of GFP. For the control condition of the oligonucleotide array experiment, either wildtype Oregon R were used or flies generated by transposon excision of the $\mathrm{k} b r a t^{k 06028} \mathrm{P}$ element. Excision of the brat ${ }^{k 06028}$ transposon resulted in several viable strains, which were further characterized by genomic PCR. Using the primer pair 5'AACAACCAAAACAACGGCAACC $3^{\prime}$ and 5' AAACGGAGATAAGCCGACTTAC 3', flanking the insertion site of the brat ${ }^{206028}$ transposon in the brat genomic DNA, a fragment of $211 \mathrm{bp}$ was PCR amplified and sequenced from both strands. For all characterized strains, this sequence was indistinguishable from the genomic brat sequence of Oregon R control flies; strain "bratk06028 jumpout" was chosen for further work. For assessing the percentage of adult escapers in brat ${ }^{k 06028}$, homozygous third instar larvae were identified by the absence of GFP, counted $(n=979)$ and collected into bottles containing standard food. Bottles were then subsequently checked on a daily basis for hatched flies during the following 4 weeks. All flies were kept on standard cornmeal/ yeast/ agar medium at $25^{\circ} \mathrm{C}$.

\section{Histology}

For sectioning, adult flies were fixed, dehydrated, embedded in paraffin, and cut into $7 \mu \mathrm{m}$ sections as described by Heisenberg and Böhl [88]. Sections were mounted on coated glass slides with DePeX (Fluka), and neural structures were visualized with a Zeiss Axioskop microscope by autofluorescence (wavelength $488 \mathrm{~nm}$ ) and recorded using a Prog/Res/3008 digital camera (Kontron, Zürich).

\section{Experimental paradigms and oligonucleotide arrays}

Two oligonucleotide array experiments were carried out. In the first experiment, a custom-designed Drosophila oligonucleotide array (roDROMEGAa, Affymetrix) was used [89]. This array contains 14,090 sequences representing 13,369 single transcripts encoding Drosophila proteins deposited in SWISS-PROT/TrEMBL databases (Celera Genome/BDGP Release no.1; [10] as well as prokaryotic and custom chosen control sequences. This array was used to compare the transcriptome from Oregon $\mathrm{R}$ control heads with heads of homozygous bratk06028 flies; 5 replicates were done for the wildtype condition and 6 were done for homozygous brat ${ }^{k 06028}$ (experiment A). In the second experiment, a commercially available Affymetrix Drosophila full genome array was used (Drosophila Genome Array, Affymetrix) which contains probe sets interrogating more than 13,500 genes from Drosophila melanogaster (experiment B). Sequences used to design this array can be found in Flybase (version 1). Over 8,000 of the genes represented have at least one EST/cDNA match. Additionally, approximately 5,500 genes were identified using prediction algorithms. This array was used to compare the transcriptome of dissected Drosophila brains derived from brat ${ }^{k 06028}$ jumpout with that of homozygous brat ${ }^{k 06028}$ brains. 6 replicates were done for each of the two conditions.

\section{Preparation of biotinylated cRNA}

Total RNA was isolated from 100 fly heads or 150 fly brains, respectively, using guanidinium isothiocyanate in combination with acidic phenol ( $\mathrm{pH}$ 4.3) (fast RNA tube green kit from BIO101) in a fast prep homogenizer FP120 (Bio 101). After precipitation, RNA was dissolved in DEPC-treated water (Ambion) and spectrophotometrically quantified using a GeneQuant RNA/DNA calculator (Pharmacia Biotech). The quality of the RNA was checked on a $0.5 \times$ TBE agarose gel and the samples were stored at $-80^{\circ} \mathrm{C}$. cDNA was synthesized upon total RNA as a template, using the SuperScript Choice System for cDNA synthesis (Gibco/BRL) with a T7-(T)24 DNA primer. This primer (5'-GGCCAGTGAATTGTAATACGACTCACTATAGGGAGGCGG-(T)24VN-3') was PAGE-gel purified. For first strand cDNA synthesis, a typical $40 \mu$ l reaction contained 10-15 $\mu$ g RNA, 200 pmoles T7-(T)24 primer, 500 $\mu \mathrm{M}$ of each dNTPs and 800 units reverse transcriptase (AMV Superscript II). The reaction was incubated for one hour at $42^{\circ} \mathrm{C}$. Second strand cDNA synthesis was carried out at $18^{\circ} \mathrm{C}$ for two hours in a total volume of $340 \mu \mathrm{l}$, using 20 units E. coli DNA ligase, 80 units E. coli DNA polymerase I and 4 units RNase $\mathrm{H}$ in the presence of 250 $\mu \mathrm{M}$ of each dNTP. After 2nd strand cDNA synthesis, $0.5 \mu \mathrm{l}$ RNase A (100 mg/ml) (Qiagen) was added and the samples were incubated at $37^{\circ} \mathrm{C}$ for half an hour. Thereafter $7.5 \mu \mathrm{l}$ proteinase $\mathrm{K}(10 \mathrm{mg} / \mathrm{ml})$ (Sigma) was added and the samples were further incubated at $37^{\circ} \mathrm{C}$ another half hour. After cDNA synthesis was completed, samples were phenol-chloroform extracted (3 times) using Phase Lock Gel (5 Prime-3 Prime, Inc.) and precipitated overnight at $-20^{\circ} \mathrm{C}$ with 2.5 volumes $100 \%$ ethanol. After percipitation, the samples were stored at $-20^{\circ} \mathrm{C}$. Biotinylated antisense cRNA was synthesized from the dsDNA template, 
using T7 RNA polymerase (MEGAscript T7 Kit, Ambion, Inc.).

A $20 \mu \mathrm{l}$ reaction volume contained between $0.3-1.5 \mu \mathrm{g}$ cDNA, $7.5 \mathrm{mM}$ of both ATP and GTP, $5.6 \mathrm{mM}$ of both UTP and CTP and $1.8 \mathrm{mM}$ of both biotinylated Bio-16UTP and Bio-11-CTP (ENZO diagnostics) and $2 \mu \mathrm{l} 10 \times \mathrm{T} 7$ enzyme mix. The reaction was incubated at $37^{\circ} \mathrm{C}$ for 8 hours. Thereafter the unincorporated NTPs were removed by putting the sample over an RNeasy spin column (Qiagen). Aliquots of the reaction before and after cRNA synthesis were analyzed by agarose gel electrophoresis. Samples were precipitated overnight at $-20^{\circ} \mathrm{C}$, taken up in $20 \mu \mathrm{l}$ DEPC treated water and spectrophotometrically quantified. Susequently, the biotinylated antisense cRNA was fragmented by heating the sample to $95^{\circ} \mathrm{C}$ for $35 \mathrm{~min}$ in a volume of $25 \mu \mathrm{l}$, containing $40 \mathrm{mM}$ tris-acetate $(\mathrm{pH}$ 8.1), $100 \mathrm{mM} \mathrm{KOAc}, 30 \mathrm{mM} \mathrm{MgOAc}$. After the fragmentation, the samples were placed on ice.

\section{Hybridization and Scanning}

Gene chips were equilibrated at RT and prehybridized with $280 \mu$ l hybridization buffer $(1 \times$ MES $(\mathrm{pH} 6.7) / 1 \mathrm{M}$ $\mathrm{NaCl} / 20 \mathrm{mM}$ EDTA/ $0.01 \%$ Tween 20) for $15 \mathrm{~min}$ at $45^{\circ} \mathrm{C}$ with rotation at $60 \mathrm{rpm}$. Hybridization was done for $16 \mathrm{~h}$ at $45^{\circ} \mathrm{C}(60 \mathrm{rpm})$ in a final volume of $220 \mu \mathrm{l} \mathrm{hybrid-}$ ization buffer, $0.1 \mathrm{mg} / \mathrm{ml}$ herring sperm DNA, $0.5 \mathrm{mg} / \mathrm{ml}$ acetylated BSA containing $50 \mathrm{pM}$ control oligo B2, spiked bacterial control RNAs (BioB, BioC, BioD, cre) and $15 \mu \mathrm{g}$ fragmented biotinylated cRNA. After hybridization, the arrays were briefly rinsed with $6 \times$ SSPE-T buffer $(0.9 \mathrm{M}$ $\mathrm{NaCl} / 0.06 \mathrm{M} \mathrm{NaH}_{2} \mathrm{PO}_{4} / 6 \mathrm{mM}$ EDTA/ 0.01 \%Tween 20). Washing and staining were carried out on a Fluidics station 400 (Affymetrix, MAS 5.0) using $100 \mathrm{mM}$ MES, $0.1 \mathrm{M}$ $\mathrm{NaCl}, 0,01 \%$ Tween 20 as stringent wash buffer. Two different staining protocols were used. When comparing the transcriptome of Oregon R fly heads and homozygous brat ${ }^{k 06028}$ fly heads, staining was carried out in $220 \mu \mathrm{l} 1 \times$ MES buffer, $2.0 \mathrm{mg} / \mathrm{ml}$ acetylated BSA, $10 \mathrm{ng} / \mathrm{ml}$ StreptavidinR-phycoerythrin conjugate (Molecular Probes) at $40^{\circ} \mathrm{C}$ for $15 \mathrm{~min}$. In the second experiment comparing dissected brains of brat ${ }^{k 06028}$ jumpout flies with homozygous brat ${ }^{k 06028}$ brains, an additional antibody amplification step was included. Prior to staining, $220 \mu \mathrm{l}$ $1 \times$ MES buffer containing $2 \mathrm{mg} / \mathrm{ml}$ acetylated BSA and 2 $\mu \mathrm{g} / \mathrm{ml}$ biotinylated anti-streptavidin antibody (Vector) was applied onto the array for $30 \mathrm{~min}$ at $40^{\circ} \mathrm{C}$. Following a washing step, staining was then performed using streptavidinR-phycoerythrin as described above. Following a final washing step, arrays were scanned with a commercial confocal laser scanner (Agilent).

\section{Data analysis}

The single arrays were analysed using Microarray Suite 5.0 (Affymetrix). Detailed analysis was carried out using Race-
A (Roche), Excel2000 and Access2000 software (Microsoft), and GeneSpring (Silicon Genetics). In this process, the mean of all signal values of each array were set to 1 , and all other signal values were expressed relative to it (normalization). A Nalimov outlier test was performed [90]. The data was grouped into control- and experimental conditions. For every gene in all 4 conditions a single mean signal value over the replicates was calculated. Also an unpaired t-test was performed for every gene per experiment to assess significance of change between conditions. The annotation of the two different arrays was linked (see below) using information from NetAffx [91] and Flybase [92]. Genes were judged as present when their presence attribute in the RACE-A software was above 0.75 . Both datasets were filtered using a cutoff on the mean signal ( $\geq 10$ in the condition the gene had to be present in), the changefold $(\geq 2)$ and the $t$-test $(\leq 0.0001)$. The various control sequences present on the arrays were excluded from analysis. Subsequently the overlap of the two datasets was calculated using the database mentioned above. When more than one probe set was representing a gene the probe set with the highest statistical significance as judged by the t-test was chosen. In those cases were the pvalue was identical, the probe set with the higher expression levels was chosen. The raw data of the two experiments can be found in Supplementary Table 1 and Supplementary Table 2 [see Additional files 1 and 2].

\section{Linking the two different oligonucleotide arrays}

Using the probe set annotation information provided for the roDROMEGa array, we determined which probe sets on the Affymetrix "DrosGenome1" GeneChip were analogous to those on the Roche custom chip. To this end, a database was built with the following information: 1) Affymetrix "DrosGenome1" probe set annotations, 2) roDROMEGa annotations, and 3) FlyBase gene annotations.

The Affymetrix "DrosGenome1" annotations were extracted from the June 2003 DrosGenome1_annot_csv.zip file obtained from the NetAffx [91] Affymetrix web site http://www.affyme trix.com/Auth/analysis/

downloadtaDrosGenome1_annot_csv.zip. The database tables contained probe set ID, gene symbol, FlyBase FBgns, and synonyms as annotated by Affymetrix for each of the 14,010 probe sets on DrosGenome1. The roDROMEGa array annotations were extracted from text dump files obtained from Roche. The database table contained probe set ID and gene symbol information for each of the 14,090 probe sets on the Roche custom chip. FlyBase gene annotations were extracted from the 29-082003 FlyBase genes dump file located at ftp://flybase.org/ flybase/genes/genes.txt. The resulting database tables contained gene symbol, FBgns, and synonyms for all 43,177 
annotations in FlyBase. During extraction of Affymetrix DrosGenome1 and FlyBase annotations from their source files, special cleanup was required to correct from HTML escape characters commonly used in Drosophila melanogaster annotation dump files. This was necessary because the annotations for the roDROMEGa array contained only fully spelled out words for gene symbols (i.e. 'alphaCop' instead of '\&agr;Cop').

The 14,090 probe sets on the Roche custom Drosophila microarray represented 13,343 distinct genes which were mapped to Affymetrix's DrosGenome1. Utilizing the database described above, we first mapped gene symbols annotated by Roche on their custom chip to gene symbols and synonyms annotated by Affymetrix on their DrosGenome1 chip. This search yielded 13,377 probe sets $(12,784$ genes $)$ on the Roche Drosophila custom chip. The remaining 713 probe sets on the Roche custom chip which had no direct gene symbol or synonym match to DrosGenome1 were used in a three-way search using FlyBase genes data. These 713 Roche gene symbols were searched against all FlyBase gene symbols and synonyms and in case of a match all the corresponding FlyBase FBgns for these genes were used to search the Affymetrix FBgn annotations on DrosGenome1. This search resulted in additional 449 probe sets (401 genes) on the Roche Drosophila custom chip which mapped to analogous probe sets on DrosGenome1. Of the remaining 172 unmapped Roche probe sets, 92 were found to be either Affymetrix AFFX controls, Roche internal controls, or rRNA controls. Thus, 13,826 Roche probe sets $(13,185$ genes) have at least one analogous Affymetrix DrosGenome1 probe set. 172 probe sets (157 genes) on the Roche Drosophila custom chip dolfed our parameters and remained orphaned with no Affymetrix DrosGenome1 match. A list with the orphaned probe sets can be found in Supplementay Table 4 [see Additional file 4]

\section{Functional classification and links to mammalian homologs involved in cancer}

The 321 genes differentially regulated in both experiments were grouped into functional classes by reviewing their annotation in Flybase. When there were vertebrate homologs annotated in Flybase we searched the PubMed bibliographic database http://www.ncbi.nlm.nih.gov/ PubMed/medline.html for literature that linked the gene in question to cancer in vertebrates.

\section{Authors' contributions}

TL carried out the the array study of experiment B, performed the histology of flyheads, did the bioinformatics and statistics for both chip experiments and drafted the manuscript. RL carried out the array study of experiment A and performed the jumpout of the bratk06028 P-element.
US dissected the flies that were used as a tissue source for the RNA extractions. LH carried out the bioinformatics for linking the annotations of the two different array platforms used in our study. BE balanced the fly strains. FX was initially involved in setting up experimental conditions and carried out pilot experiments. MP, UC, KFF and HR participated in the design and coordination of the study. FH conceived of the study, and participated in its design and coordination. All authors read and approved the final manuscript.

\section{Additional material}

\section{Additional File 1}

Raw data of experiment $A$ after analysis with the RACE-A package. Column 1: probeset ID, column 2: gene symbol, column 3: mean signal for Oregon $R$ heads, column 4: mean signal for brat ${ }^{\mathrm{k} 06028}$ heads, column 5: fold change between conditions, column 6: T-test describing significance of change between conditions.

Click here for file

[http://www.biomedcentral.com/content/supplementary/1471-

2164-5-24-S1.xls]

\section{Additional File 2}

Raw data of experiment $B$ after analysis with the RACE-A package. Column 1: gene symbol, column 2: Flybase gene identifier, column 3: mean signal for A2 brains, column 4: mean signal for brat ${ }^{\mathrm{k} 06028}$ brains, column 5: fold change between conditions, column 6: T-test describing significance of change between conditions.

Click here for file

[http://www.biomedcentral.com/content/supplementary/14712164-5-24-S2.xls]

\section{Additional File 3}

All 321 genes the 2 experiments agree on as being differentially expressed between wildtype control and brat ${ }^{\mathrm{k} 06028}$. Column 1: gene symbol, column 2: Flybase gene identifier, column 3: fold change between conditions of experiment A, column 4: fold change between conditions of experiment $B$. Click here for file

[http://www.biomedcentral.com/content/supplementary/1471-

2164-5-24-S3.xls]

\section{Additional File 4}

The 172 probe sets of the roDROMEGa array that could not be linked to any probe set on the Affymetrix Drosophila genome 1 array. Column 1: roDROMEGa probe set ID, column 2: gene symbol.

Click here for file

[http://www.biomedcentral.com/content/supplementary/14712164-5-24-S4.xls]

\section{Additional File 5}

List of references to the literature used for table 2 - mammalian homologs of genes differentially regulated in brat $\mathrm{k}^{\mathrm{k} 06028}$ neoplastic tissue.

Click here for file

[http://www.biomedcentral.com/content/supplementary/14712164-5-24-S5.doc] 


\section{Acknowledgements}

We thank Martin Müller and Bruno Bello for comments on the manuscript. We also thank Clemens Broger, Martin Strahm, and Martin Neeb (F. Hoffman-La Roche) for support with the RACE-A software. We are grateful to the students of the Neurogenomics course 2002 for actively participating in this project, to Philippe Demougin for help with the array hybridizations and to Margit Böhler for assistance with the histology. This research was supported by grants from the SNSF and Neurex/Eltem

\section{References}

I. Hanahan D, Weinberg RA: The hallmarks of cancer. Cell 2000, I 00(I):57-70.

2. Evan Gl, Vousden $\mathrm{KH}$ : Proliferation, cell cycle and apoptosis in cancer. Nature 200 I, 4 I I (6835):342-348.

3. Ponder BA: Cancer genetics. Nature 200 I, 4 I I (6835):336-34I.

4. Wechsler-Reya R, Scott MP: The developmental biology of brain tumors. Annu Rev Neurosci 200I, 24:385-428.

5. Kozmik Z, Sure U, Ruedi D, Busslinger M, Aguzzi A: Deregulated expression of PAX5 in medulloblastoma. Proc Natl Acad Sci U S A 1995, 92(1 2):5709-57/3.

6. Rasheed BK, Bigner SH: Genetic alterations in glioma and medulloblastoma. Cancer Metastasis Rev I99I, I 0(4):289-299.

7. Yokota N, Aruga J, Takai S, Yamada K, Hamazaki M, Iwase T, Sugimura $\mathrm{H}$, Mikoshiba $\mathrm{K}$ : Predominant expression of human zic in cerebellar granule cell lineage and medulloblastoma. Cancer Res 1996, 56(2):377-383.

8. Holland EC: Brain tumor animal models: importance and progress. Curr Opin Oncol 200I, I3(3): I43-I47.

9. Bate M, Martinez-Arias A: The Development of Drosophila melanogaster. Cold Spring Harbor Cold Spring Harbor Laboratory Press; 1993.

10. Adams MD, Celniker SE, Holt RA, Evans CA, Gocayne JD, Amanatides PG, Scherer SE, Li PW, Hoskins RA, Galle RF, et al:: The Genome Sequence of Drosophila melanogaster. Science 2000, 287:2185-2218.

II. Rubin GM, Yandell MD, Wortman JR, Gabor Miklos GL, Nelson CR Hariharan IK, Fortini ME, Li PW, Apweiler R, Fleischmann W, et al.: Comparative Genomics of the Eukaryotes. Science 2000, 287(546I):2204-22I8.

12. Fortini ME, Skupski MP, Boguski MS, Hariharan IK: A survey of human disease gene counterparts in the Drosophila genome. J Cell Biol 2000, I 50(2):F23-30.

13. Gateff E: Malignant neoplasms of genetic origin in Drosophila melanogaster. Science 1978, 200(4349): |448-|459.

14. St John MA, Xu T: Understanding human cancer in a fly? $A m ~ J$ Hum Genet 1997, 6 I(5):1006-1010.

15. Pagliarini RA, Xu T: A genetic screen in Drosophila for metastatic behavior. Science 2003, 302(5648): | 227-I23I.

16. Potter C], Turenchalk GS, Xu T: Drosophila in cancer research. An expanding role. Trends Genet 2000, I 6(I):33-39.

17. Reiter LT, Potocki L, Chien S, Gribskov M, Bier E: A systematic analysis of human disease-associated gene sequences in Drosophila melanogaster. Genome Res 200 I, I I (6): I I |4- I I 25.

18. De Lorenzo C, Mechler BM, Bryant PJ: What is Drosophila telling us about cancer? Cancer Metastasis Rev 1999, I 8(2):295-3 I I.

19. Karim FD, Rubin GM: Ectopic expression of activated Ras I induces hyperplastic growth and increased cell death in Drosophila imaginal tissues. Development 1998, I 25(I): I-9.

20. Lowy DR, Willumsen BM: Function and regulation of ras. Annu Rev Biochem 1993, 62:851-89|.

21. Xu T, Wang W, Zhang S, Stewart RA, Yu W: Identifying tumor suppressors in genetic mosaics: the Drosophila lats gene encodes a putative protein kinase. Development 1995, I 2 I(4): 1053-1063.

22. St John MA, Tao W, Fei X, Fukumoto R, Carcangiu ML, Brownstein DG, Parlow AF, McGrath J, Xu T: Mice deficient of Lats I develop soft-tissue sarcomas, ovarian tumors and pituitary dysfunction. Nat Genet 1999, 2 I (2): I82-186.

23. Xia H, Qi H, Li Y, Pei J, Barton J, Blackstad M, Xu T, Tao W: LATS I tumor suppressor regulates $\mathrm{G} 2 / \mathrm{M}$ transition and apoptosis. Oncogene 2002, 2 I(8): | 233-|24|.

24. Turenchalk GS, St John MA, Tao W, Xu T: The role of lats in cell cycle regulation and tumorigenesis. Biochim Biophys Acta 1999 | 424(2-3):M9-MI6.
25. Tapon N, Harvey KF, Bell DW, Wahrer DC, Schiripo TA, Haber DA, Hariharan IK: salvador Promotes both cell cycle exit and apoptosis in Drosophila and is mutated in human cancer cell lines. Cell 2002, I I 0(4):467-478.

26. Torok M, Etkin LD: Two B or not two B? Overview of the rapidly expanding B-box family of proteins. Differentiation 200I, 67(3):63-7I.

27. Jensen K, Shiels C, Freemont PS: PML protein isoforms and the RBCC/TRIM motif. Oncogene 200I, 20(49):7223-7233.

28. Arama E, Dickman D, Kimchie Z, Shearn A, Lev Z: Mutations in the beta-propeller domain of the Drosophila brain tumor (brat) protein induce neoplasm in the larval brain. Oncogene 2000 , I9(33):3706-3716.

29. Sonoda J, Wharton RP: Drosophila Brain Tumor is a translational repressor. Genes Dev 200I, I 5(6):762-773.

30. Frank DJ, Edgar BA, Roth MB: The Drosophila melanogaster gene brain tumor negatively regulates cell growth and ribosomal RNA synthesis. Development 2002, I 29(2):399-407.

31. Edwards TA, Wilkinson BD, Wharton RP, Aggarwal AK: Model of the brain tumor-Pumilio translation repressor complex. Genes Dev 2003, I 7(20):2508-25I3.

32. Hankins G: Analysis of a Drosophila neuroblastoma gene. PhD thesis Department of Biology, University of Virginia, Charlottesville 1991:107.

33. Kurzik-Dumke U, Phannavong B, Gundacker D, Gateff E: Genetic, cytogenetic and developmental analysis of the Drosophila melanogaster tumor suppressor gene lethal(2)tumorous imaginal discs (I(2)tid). Differentiation 1992, 5 I(2):9|-I04.

34. Woodhouse E, Hersperger E, Shearn A: Growth, metastasis, and invasiveness of Drosophila tumors caused by mutations in specific tumor suppressor genes. Dev Genes Evol 1998, 207(8):542-550.

35. Bonini NM, Leiserson WM, Benzer S: The eyes absent gene: genetic control of cell survival and differentiation in the developing Drosophila eye. Cell 1993, 72(3):379-395.

36. Cutforth $T$, Gaul U: A methionine aminopeptidase and putative regulator of translation initiation is required for cell growth and patterning in Drosophila. Mech Dev 1999, 82(I2):23-28.

37. Alsina B, Corominas M, Berry MJ, Baguna J, Serras F: Disruption of selenoprotein biosynthesis affects cell proliferation in the imaginal discs and brain of Drosophila melanogaster. J Cell Sci 1999, I I 2(Pt I 7):2875-2884.

38. Driscoll M, Gerstbrein B: Dying for a cause: invertebrate genetics takes on human neurodegeneration. Nat Rev Genet 2003, 4(3): $181-194$

39. Saunders RD, Avides MC, Howard T, Gonzalez C, Glover DM: The Drosophila gene abnormal spindle encodes a novel microtubule-associated protein that associates with the polar regions of the mitotic spindle. J Cell Biol 1997, I37(4):88I-890.

40. Dawson IA, Roth S, Akam M, Artavanis-Tsakonas S: Mutations of the fizzy locus cause metaphase arrest in Drosophila melanogaster embryos. Development 1993, I I 7( I):359-376.

41. Scaerou F, Aguilera I, Saunders R, Kane N, Blottiere L, Karess R: The rough deal protein is a new kinetochore component required for accurate chromosome segregation in Drosophila. J Cell Sci I999, I I 2(Pt 2 I):3757-3768.

42. Manak JR, Mitiku N, Lipsick JS: Mutation of the Drosophila homologue of the Myb protooncogene causes genomic instability. Proc Natl Acad Sci U S A 2002, 99( I I ):7438-7443.

43. Ohnuma S, Philpott A, Harris WA: Cell cycle and cell fate in the nervous system. Curr Opin Neurobiol 200I, I I (I):66-73.

44. Ohnuma S, Harris WA: Neurogenesis and the cell cycle. Neuron 2003, 40(2): 199-208.

45. Tenev T, Zachariou A, Wilson R, Paul A, Meier P: Jafrac2 is an IAP antagonist that promotes cell death by liberating Dronc from DIAPI. Embo J 2002, 2 I (19):5I I8-5 I 29.

46. Frank $D J$, Roth MB: ncl-I is required for the regulation of cell size and ribosomal RNA synthesis in Caenorhabditis elegans. J Cell Biol 1998, I40(6): | 32 |- I 329.

47. Lasko P: The drosophila melanogaster genome: translation factors and RNA binding proteins. I Cell Biol 2000, I 50(2):F5 I-56.

48. Lambertsson A: The minute genes in Drosophila and their molecular functions. Adv Genet 1998, 38:69-I34. 
49. Andrulis ED, Werner J, Nazarian A, Erdjument-Bromage $H$, Tempst $\mathrm{P}$, Lis JT: The RNA processing exosome is linked to elongating RNA polymerase II in Drosophila. Nature 2002, 420(69| 7):837-84I.

50. Mount SM, Salz HK: Pre-messenger RNA processing factors in the Drosophila genome. J Cell Biol 2000, I 50(2):F37-44.

5I. Schenkel H, Hanke S, De Lorenzo C, Schmitt R, Mechler BM: P elements inserted in the vicinity of or within the Drosophila snRNP SmD3 gene nested in the first intron of the Ornithine Decarboxylase Antizyme gene affect only the expression of SmD3. Genetics 2002, I6I(2):763-772.

52. Broadus J, Fuerstenberg S, Doe CQ: Staufen-dependent localization of prospero mRNA contributes to neuroblast daughtercell fate. Nature 1998, 39 I(6669):792-795.

53. Ito T, Tyler JK, Kadonaga JT: Chromatin assembly factors: a dual function in nucleosome formation and mobilization? Genes Cells 1997, 2(10):593-600.

54. Grewal SI, Elgin SC: Heterochromatin: new possibilities for the inheritance of structure. Curr Opin Genet Dev 2002, I 2(2): | $78-187$.

55. Steffensen S, Coelho PA, Cobbe N, Vass S, Costa M, Hassan B, Prokopenko SN, Bellen H, Heck MM, Sunkel CE: A role for Drosophila SMC4 in the resolution of sister chromatids in mitosis. Curr Biol 200I, I I(5):295-307.

56. Tye BK: MCM proteins in DNA replication. Annu Rev Biochem 1999, 68:649-686.

57. Treisman JE, Follette PJ, O'Farrell PH, Rubin GM: Cell proliferation and DNA replication defects in a Drosophila MCM2 mutant. Genes Dev 1995, 9(14): 1709-17|5.

58. Gerbi SA, Bielinsky AK: DNA replication and chromatin. Curr Opin Genet Dev 2002, I 2(2):243-248.

59. Leatherman JL, Jongens TA: Transcriptional silencing and translational control: key features of early germline development. Bioessays 2003, 25(4):326-335.

60. Beltran S, Blanco E, Serras F, Perez-Villamil B, Guigo R, Artavanis-Tsakonas S, Corominas M: Transcriptional network controlled by the trithorax-group gene ash2 in Drosophila melanogaster. Proc Natl Acad Sci U S A 2003, I00(6):3293-3298.

61. Hemavathy K, Ashraf SI, IP YT: Snail/slug family of repressors: slowly going into the fast lane of development and cancer. Gene 2000, 257(I): I-12.

62. Rudolph KM, Liaw G], Daniel A, Green P, Courey AJ, Hartenstein V, Lengyel JA: Complex regulatory region mediating tailless expression in early embryonic patterning and brain development. Development 1997, I 24(2I):4297-4308.

63. Wallace $\mathrm{K}$, Liu TH, Vaessin $\mathrm{H}$ : The pan-neural bHLH proteins DEADPAN and ASENSE regulate mitotic activity and cdk inhibitor dacapo expression in the Drosophila larval optic lobes. Genesis 2000, 26(I):77-85.

64. Edenfeld G, Pielage J, Klambt C: Cell lineage specification in the nervous system. Curr Opin Genet Dev 2002, I 2(4):473-477.

65. Hitier R, Chaminade M, Preat T: The Drosophila castor gene is involved in postembryonic brain development. Mech Dev 200I, 103(I-2):3-II.

66. Saucedo LJ, Edgar BA: Why size matters: altering cell size. Curr Opin Genet Dev 2002, I 2(5):565-57I.

67. Skeath JB, Thor S: Genetic control of Drosophila nerve cord development. Curr Opin Neurobiol 2003, I 3(I):8-15.

68. Boquet I, Boujemaa R, Carlier MF, Preat T: Ciboulot regulates actin assembly during Drosophila brain metamorphosis. Cell 2000, I02(6):797-808.

69. Hassan B, Vaessin H: Regulatory interactions during early neurogenesis in Drosophila. Dev Genet 1996, 18(1):18-27.

70. Baker SE, Lorenzen JA, Miller SW, Bunch TA, Jannuzi AL, Ginsbers $\mathrm{MH}$, Perkins LA, Brower DL: Genetic interaction between integrins and moleskin, a gene encoding a Drosophila homolog of importin-7. Genetics 2002, I 62(I):285-296.

7I. Radtke F, Raj K: The role of Notch in tumorigenesis: oncogene or tumor suppressor? Nat Rev Cancer 2003, 3( I 0):756-767.

72. Cavallaro $U$, Christofori $G$ : Cell adhesion in tumor invasion and metastasis: loss of the glue is not enough. Biochim Biophys Acta 200I, I 552(I):39-45

73. Tepass U, Tanentzapf G, Ward R, Fehon R: Epithelial cell polarity and cell junctions in Drosophila. Annu Rev Genet 2001, 35:747-784.
74. Kussel P, Frasch M: Pendulin, a Drosophila protein with cell cycle-dependent nuclear localization, is required for normal cell proliferation. J Cell Biol 1995, I 29(6): I49I-1507.

75. El-Husseini AE, Fretier P, Vincent SR: Cloning and characterization of a gene (RNF22) encoding a novel brain expressed ring finger protein (BERP) that maps to human chromosome I I p I5.5. Genomics 200I, 7 I(3):363-367.

76. Reymond A, Meroni G, Fantozzi A, Merla G, Cairo S, Luzi L, Riganelli D, Zanaria E, Messali S, Cainarca S, et al:: The tripartite motif family identifies cell compartments. Embo J 200I, 20(9):2 I40-2 I5I.

77. Koi M, Johnson LA, Kalikin LM, Little PF, Nakamura Y, Feinberg AP: Tumor cell growth arrest caused by subchromosomal transferable DNA fragments from chromosome II. Science 1993 , 260(5 I06):36I-364.

78. Schiebe M, Ohneseit $P$, Hoffmann W, Meyermann R, Rodemann HP, Bamberg M: Loss of heterozygosity at IIpI 5 and $p 53$ alterations in malignant gliomas. I Cancer Res Clin Oncol 200I, I 27(5):325-328.

79. Ngan ES, Hashimoto Y, Ma ZQ, Tsai MJ, Tsai SY: Overexpression of Cdc25B, an androgen receptor coactivator, in prostate cancer. Oncogene 2003, 22(5):734-739.

80. Blask DE, Sauer LA, Dauchy RT, Holowachuk EW, Ruhoff MS, Kopff HS: Melatonin inhibition of cancer growth in vivo involves suppression of tumor fatty acid metabolism via melatonin receptor-mediated signal transduction events. Cancer Res 1999, 59( I 8):4693-470|.

8I. Todorov IT, Werness BA, Wang HQ, Buddharaju LN, Todorova PD, Slocum HK, Brooks JS, Huberman JA: HsMCM2/BM28: a novel proliferation marker for human tumors and normal tissues. Lab Invest 1998, 78(I):73-78.

82. Levens DL: Reconstructing MYC. Genes Dev 2003, 17(9): 107|-1077.

83. Jin J, Harper JW: A license to kill: transcriptional activation and enhanced turnover of Myc by the SCF(kp2) ubiquitin ligase. Cancer Cell 2003, 3(6):5I7-5I8.

84. Zhu Y, Parada LF: The molecular and genetic basis of neurological tumors. Nat Rev Cancer 2002, 2(8):6I6-626.

85. Weis K: Regulating access to the genome: nucleocytoplasmic transport throughout the cell cycle. Cell 2003, I I 2(4):44| -45 I.

86. Ruggero $D$, Pandolfi PP: Does the ribosome translate cancer? Nat Rev Cancer 2003, 3(3): 179-192.

87. Albertson R, Doe CQ: DIg, Scrib and Lgl regulate neuroblast cell size and mitotic spindle asymmetry. Nat Cell Biol 2003, 5(2): $166-170$.

88. Heisenberg M, Böhl K: Isolation of anatomical brain mutants of Drosophila by histological means. Z Naturforsch 1979, 34:143-147.

89. Montalta-He H, Leemans R, Loop T, Strahm M, Certa U, Primig M, Acampora D, Simeone A, Reichert $H$ : Evolutionary conservation of otd/Otx2 transcription factor action: a genome-wide microarray analysis in Drosophila. Genome Biol 2002, 3(4):RESEARCHOOI5.

90. Kaiser R, Gottschalk G: Elementare Tests zur Beurteilung von Meßbdaten. Bibliographisches Institut Mannheim/Wien/Zürich $B$ Wissenschaftsverlag. 1972.

91. Liu G, Loraine AE, Shigeta R, Cline M, Cheng J, Valmeekam V, Sun S, Kulp D, Siani-Rose MA: NetAffx: Affymetrix probesets and annotations. Nucleic Acids Res 2003, 3I(I):82-86.

92. The FlyBase database of the Drosophila genome projects and community literature. Nucleic Acids Res 2003, 3 I ( I): I 72- 175. 